\title{
LA CARTOGRAFÍA EN EL CATASTRO DE ENSENADA, 1750-1756
}

\author{
POR \\ CONCEPCIÓN CAMARERO BULLÓN
}

Este artículo ${ }^{1}$ pretende poner de manifiesto cuáles fueron los propósitos y resultados cartográficos que abrigaron y obtuvieron respectivamente los diseñadores y realizadores de la averiguación catastral llevada a cabo en la Corona de Castilla entre 1750 y 1756, conocida como Catastro de Ensenada. A tal fin, el contenido se estructura en los apartados siguientes:

1. Consideración de las principales características del catastro en cuanto marco general en el que se va a generar un importante conjunto de representaciones de carácter cartográfico no técnico.

2. Normativa que se dicta para la obtención de dichas informaciones, así como la marcha atrás que se va a producir cuando se constate la escasez de geómetras y se valore debidamente el tiempo que se precisaría para medir y representar con exactitud los miles de términos que había que catastrar.

3. Resultados cartográficos obtenidos, documentos en los que quedaron plasmados y el uso de los mismos que puede hacerse ${ }^{2}$.

${ }^{1}$ Este estudio tiene su origen en una comunicación presentada al I Congreso de Cartografía Histórica, celebrado en Madrid los días 9 y 10 de febrero de 1989, cuyas actas no llegaron a publicarse.

${ }_{2}^{2}$ Este trabajo, en su mayor parte realizado en el marco del Proyecto de Investigación

Concepción Camarero Bullón: Departamento de Geografía de la Universidad Autónoma de Madrid.

Estudios Geográficos

Tomo LIX, n. ${ }^{\circ} 231$, abril-junio 
Finalmente, se resalta la contemporaneidad entre el primer intento institucional para elaborar el Atlas de España y la cartografía catastral a la que se refiere este trabajo, que se puede calificar de «popular» por haber sido elaborada, salvo contadísimas ocasiones, desde el desconocimiento de los principios del Arte correspondiente.

\section{El catastro y sus objetivos cartográficos}

En 1743, tras la muerte de José del Campillo, ocupa la Secretaría de Hacienda el marqués de la Ensenada (1702-1789), quien, al poco tiempo, comienza a acopiar información acerca del Catastro realizado en Cataluña en la segunda década del siglo. Tiene el propósito de aplicar en la Corona de Castilla, mediante sustitución, lo que en Cataluña se hizo mediante nueva planta. Así, si el catastro catalán se lleva a cabo para implantar una fiscalidad al modo de la castellana, de manera que dicho Principado realizara a la Real Hacienda una contribución equivalente a lo que venían pechando los castellanos por razón de Rentas provinciales, en Castilla el objetivo se fija en sustituir los múltiples ramos contributivos englobados bajo el epígrafe de Rentas provinciales por una contribución única aproximadamente del mismo montante. A la vez, se pretende reformar profundamente las bases de la fiscalidad, de manera que contribuyan todos los vasallos, incluidos los privilegiados, y que lo hagan de manera proporcional a la riqueza de cada uno.

En el sistema de averiguación que se debate, experimenta y finalmente se adopta en 1749 se concede gran importancia al pueblo y su término en cuanto unidad jurisdiccional, cuya riqueza se calculará como agregación de las riquezas individuales de cada uno de los vecinos,

PS95-0040 de la DGDES del Ministerio de Educación y Cultura, se ha elaborado a partir de la información recogida de la correspondencia mantenida entre los Intendentes de las 22 provincias de la Corona de Castilla y la Real Junta de Única Contribución (Archivo General de Simancas, Dirección General de Rentas, 1. ${ }^{a}$ remesa, legajos 1859-1925). Vaya mi agradecimiento para el personal de dicho archivo, muy especialmente para su jefa de sala, doña Isabel Aguirre y su director, don José Luis Rodríguez de Diego. Asimismo agradezco a doña Eva Martín, doña M. ${ }^{a}$ Dolores Torres, don Carlos Álvarez, don Carlos Flores, don Christian Madsen y don Carlos Travesí de Diego, directores de los Archivos Históricos Provinciales de Granada, Jaén, Soria, Toledo, Ciudad Real y Palencia respectivamente, y a don Floriano Ballesteros, del de la Diputación de Burgos, la ayuda prestada para la consulta de la documentación catastral en ellos custodiada. 
moradores y forasteros con propiedades en él. El método consistirá en contar, medir, valorar y averiguar todo lo que en un término había de riqueza real o potencial, ya fuesen tierras, casas, ganados, industrias, comercio o actividades financieras. Mediante la averiguación meticulosa de todo ello se obtendría finalmente una relación de pueblos, ordenados por provincias y partidos o corregimientos, y en cada uno de ellos de personas físicas y jurídicas, a cada una de las cuales se le habría calculado un producto total único, definidor de su riqueza estable. Averiguada la riqueza de toda la Corona, y sabido cuánto se venía recaudando por Rentas provinciales, el problema se reducía a calcular con qué porcentaje de la riqueza total debería contribuirse para que la Real Hacienda recaudara una cantidad aproximadamente igual a la que venía percibiendo hasta entonces.

El nuevo sistema fiscal proyectado era profundamente innovador, pues dejaba de basarse en los consumos (sisas y cientos) y en las compraventas (alcabala) para gravar los bienes inmuebles, los semovientes y las utilidades derivadas de cualquier actividad profesional o lucrativa. Era también revolucionario por cuanto supondría descargar a los pecheros del estado general de una buena parte de sus contribuciones, que pasarían a ser aportadas por los privilegiados, nobles y eclesiásticos, que por una u otra vía se habían venido liberando de la casi totalidad de las cargas.

Pero la Administración era consciente de que no se podía pasar del cero al infinito, pues carecía de capacidad recaudadora para llegar directamente a los millones de contribuyentes. De ahí que plantee que la unidad recaudatoria mínima sea el pueblo, aunque éste a su vez debería recaudar en su término la cantidad total resultante. Variante fundamental respecto al pasado sería que ahora los pueblos no recaudarían por encabezamiento o repartimiento libremente establecido en cada lugar (lo que hubiera significado perpetuar las flagrantes injusticias del sistema que se pretendía modificar) sino que debería atenerse a cobrar a cada vecino, habitante o propietario forastero el porcentaje establecido sobre la riqueza que le hubiese resultado del catastro.

Por consiguiente, el catastro se propone conocer la riqueza individual como paso obligado para valorar la riqueza local. De ahí que plantee la confección de unos Estados o cuadros estadísticos de ámbito local, en que se resumiría la riqueza de cada pueblo, así como la evacuación de un Interrogatorio de 40 preguntas referidas precisamente al término y 
pueblo en sí mismos: la principal de todas al efecto que aquí nos interesa es la tercera: «Qué territorio ocupa el término, quánto de levante a poniente, $y$ de norte a sur; y quánto de circunferencia, por horas y leguas; qué linderos o confrontaciones, y qué figura tiene, poniéndola al margen». Otra pregunta, la $10 .^{\mathrm{a}}$, recababa el dato de su superficie, que debía expresarse en las unidades de medida locales, si es que no coincidían con las unidades-patrón castellanas.

\section{Normativa dictada para la averiguación del mapa} de los términos jurisdiccionales

Los diseñadores del Catastro debían ser plenamente conscientes de las exigencias que entrañaba la cumplimentación exacta y rigurosa que tales preguntas implicaban, razón por la cual se ordenó, por real decreto de 10 de octubre de 1749, que en los equipos que habían de constituirse bajo la dirección de los intendentes para llevar a cabo las averiguaciones se integrasen geómetras y agrimensores, especialistas a los que en la época se les reconocía capacidad profesional para efectuar las mediciones y el levantamiento cartográfico de tierras. Con mayor cualificación se hallaban otros dos cuerpos, el de los geógrafos y el de los ingenieros, correspondiendo a los primeros la determinación de las coordenadas geográficas de cualquier punto del país, mientras que los segundos se ocupaban del levantamiento de mapas provinciales, costeros o temáticos y del diseño y ejecución de fortificaciones, cuarteles, puentes, caminos, canales de riego o navegación, azudes, baterías costeras, etcétera.

Cuando en los primeros meses de 1750 toman posesión los intendentes de las veintidós provincias que formaban la Corona de Castilla y se disponen a dar cumplimiento al encargo que se les ordenó como preferente - la realización del Catastro- se encuentran con que en la mayoría de las provincias no hay geómetras ni apenas agrimensores; los primeros estaban casi todos ellos integrados en el Cuerpo de ingenieros, con el rango de extraordinarios, o actuaban como ingenieros delineantes, y desde luego se hallaban prácticamente concentrados en la Corte, en las capitales de las intendencias de ejército y, sobre todo, en la capital del Principado de Cataluña, donde poco an- 
tes había entrado en funcionamiento la Academia de Matemáticas, institución en la que precisamente habían de formarse los geómetras y los ingenieros.

Los geómetras se regían por una Instrucción que databa de 1728 , la cual contemplaba dos tipos de profesionales: los Geómetras y los Expertos. Nacen unos y otros como Cuerpos de especialistas destinados a cubrir las necesidades de medición derivadas de la cobranza del catastro en Cataluña. Los salarios que se les fijaron en la Instrucción fueron de 12 reales de ardite/día a los primeros y de 10 a los segundos. Medio siglo después se unieron todos los contratados en el Real Tributo de Catastro del Principado de Cataluña en demanda de incremento salarial y de fijación de ayudas de costa, alegando que no se les había modificado el salario en medio siglo, mientras que la renta del catastro en Cataluña había ido incrementándose, alcanzando cerca de un millón de pesos en 1777. En apoyo de sus demandas manifestaban que los gastos del catastro eran mínimos, pues «sólo gasta la Real Hazienda los salarios de pocos sujetos empleados en esta dependencia». Y sobre la ayuda de costa decían sentirse discriminados, pues todos los funcionarios tenían fijada ayuda de costa o dieta para sus desplazamientos, aportando como ejemplos la de 36 reales que percibían los artistas que salían de su lugar de residencia «para algún visorio o estima», siendo mayores las de abogados, relatores o jueces; este sistema se aplicaba también en Hacienda y en el Ejército, «pues no se manda salir a oficial alguno de las contadurías y arsenales de Marina o de las Reales Atarazanas para ejercer comisiones sin que se le señale una gratificación diaria»; decían, por ejemplo, que un oficial de la Contaduría de Marina destinado a controlar el corte de madera para construcción de navíos era gratificado con 3 pesos diarios. Añadían que debía tenerse en cuenta que «el portarse con decoro, y el zelo y desinterés correspondientes a su carácter de comisionados de Su Majestad quedarian más asegurados si se les fijaban gratificaciones proporcionadas como ayuda de costa», y más cuando eran «tan graves y delicados» los asuntos que se les encomendaban.

Pero, como señalábamos antes, los geómetras eran pocos, siendo muchas las provincias donde no residía ni uno solo. Esto lleva a la Junta de Única Contribución a plantear el problema al monarca en Representación de 15 de mayo de 1750 . Basa la Junta su petición de prescindir de tales profesionales en el encarecimiento y retraso que provocaría la me- 
dición geométrica de los términos, tarea que, aunque importante, consideraba «por aora es escusable». En el ánimo de la Junta pesó sobremanera a la hora de tal propuesta al monarca el temor de que si se mandaban ejecutar con todo rigor los levantamientos cartográficos de los términos, así como lo que también se había ordenado - medir y representar cada una de las tierras (parcelas) - el catastro se haría eterno, con lo que, por conseguir el todo, se correría el riesgo de no alcanzar lo más importante: fijar una nueva base para la aplicación más justa de la fiscalidad. Propone al rey como solución que las mediciones puedan correr a cargo de «prácthicos», como los llamaba Burgos, «estimadores» (Galicia), «apreziadores» (Córdoba) o «tazmiadores» (Sevilla).

El monarca accedió a la petición de la Junta, resolviendo que se recurriese en cada pueblo «a agrimensores prácticos, que en todos los lugares hay quienes saben medir tierras con perfección a estilo del pays». Esta medida, única que podía adoptarse, va a condicionar el que la que podía haber sido la primera cartografía catastral técnica de los términos de las Castillas se vea reducida a ser la primera cartografía popular de dichas unidades territoriales.

Estaba también mandado que fueran los propios declarantes quienes en sus memoriales representaran las figuras de sus tierras «como se alcanza a la vista», es decir, muy grosso modo, y que se dieran como buenas las superficies declaradas por los interesados y aceptadas por los peritos, no procediendo a medirlas más que si hubiese instancia de parte. Y todo ello en aplicación del principio pragmático de que lo mejor en ese momento sería enemigo de lo bueno. Por eso, uno de los principales mentores del Catastro, Bartolomé Sánchez de Valencia, escribiría: «En una obra tan vasta no es fácil que consigamos, aunque nos matemos, la última perfección al primer golpe. Salga en bruto, que fácil será retocarla y pulirla, pero no por esto quiero decir que avandonemos los instrumentos».

\section{Los resultados cartográficos en la documentación catastral}

De lo expuesto hasta aquí se deducen varios aspectos que deben señalarse antes de proseguir: 
1. El catastro se plantea obtener mapas, rigurosamente elaborados por geómetras, de todos y cada uno de los más de 15.000 términos que formaban la Corona.

2. Se plantea, asimismo, obtener planos de todas y cada una de las tierras, labradas o eriales, de montes o prados, existentes en dichos términos, encomendando la tarea a agrimensores.

3. Las exigencias cartográficas iniciales se van a ver rebajadas por la inexistencia de expertos en número suficiente y por el temor de que si lo cartográfico consumía más tiempo del razonable fracasara el fin fundamental: la averiguación de la riqueza.

Con estas premisas, vamos, seguidamente, a ver algunos de los resultados obtenidos, primero en cuanto a los términos y después en cuanto a las tierras.

Las figuras de los términos quedaron recogidas en uno solo de los diversos documentos catastrales, el llamado Respuestas generales, el cual ofrece la particularidad de haberse realizado por partida doble, ya que se hicieron copias de los originales. Éstos quedaron custodiados en las contadurías provinciales, mientras que las copias se enviaron a la Real Junta de Única Contribución entre 1754 y 56, depositándose en 1832 en el Archivo General de Simancas, donde se conservan íntegras, al contrario que las otras, muchas de las cuales se han perdido.

Esto permite decir que cabe disponer, a partir de Simancas, de los mapas, generalmente sencillos, de buena parte de los términos de las Castillas. Pero también hay que advertir que, desgraciadamente, estos trazados suelen ser mucho más simples que los que se realizaron en las Respuestas originales, y, a su vez, éstos mucho más que los realizados en el campo por peritos o geómetras, de manera que la recopilación ideal sería aquella que partiera de esos primeros mapas, más los existentes en las Respuestas originales que se conservan en muchas provincias, completada con las de Simancas para aquellas que las tienen perdidas.

Sirva de ejemplo del proceso, y de lo que podría ser una recopilación ideal de la cartografía catastral, el caso de la localidad jiennense de Villardompardo, que constituye una auténtica joya por su excepcionalidad, pues, en este caso, se ha conservado la documentación de todos los pasos seguidos en la elaboración de la cartografía de la localidad: el mapa levantado por el geómetra Juan de Molina, así como la explicación del mismo y de las equivalencias de las medidas utilizadas en el término, el 


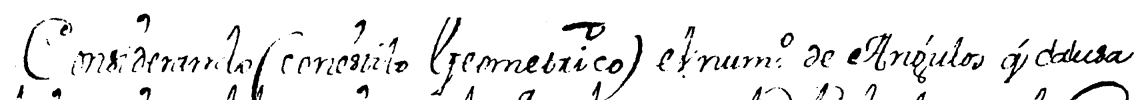

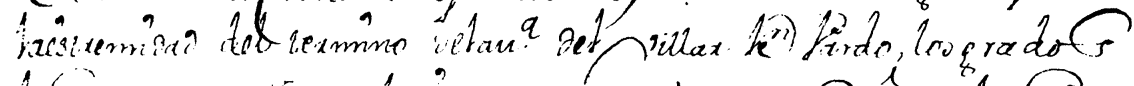

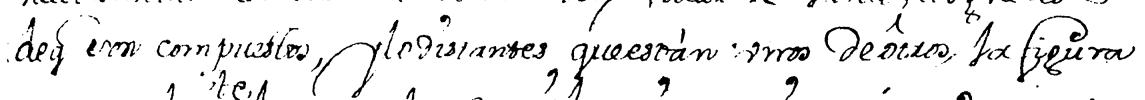

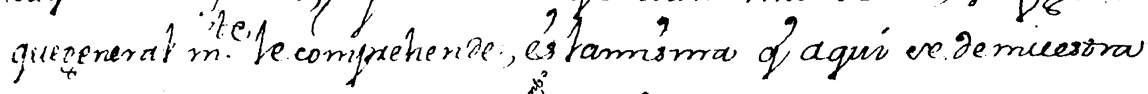

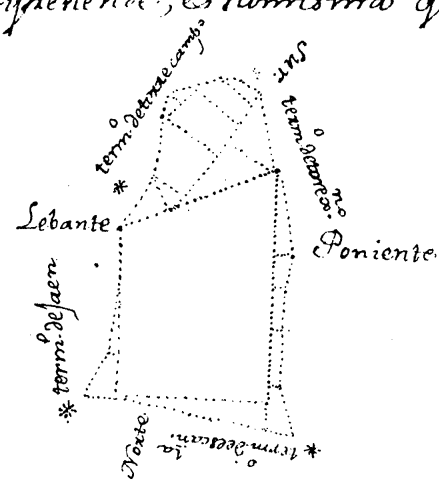

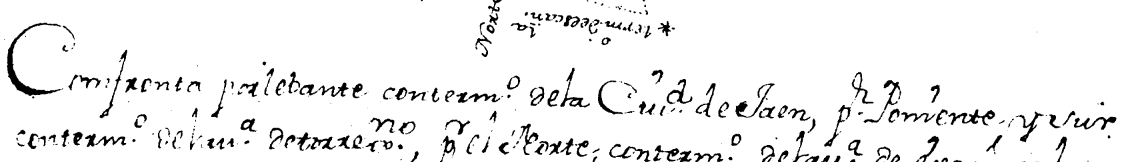

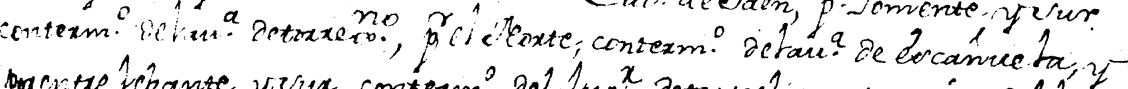

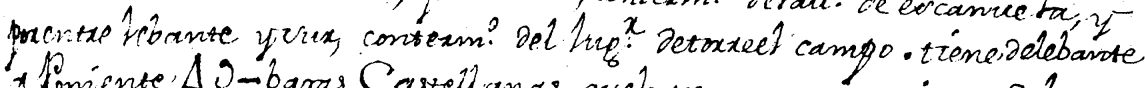
x Ponente $\Delta$ S-baras $C$ aszell an as quehacen quato quintos delequa

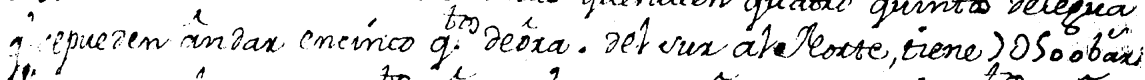

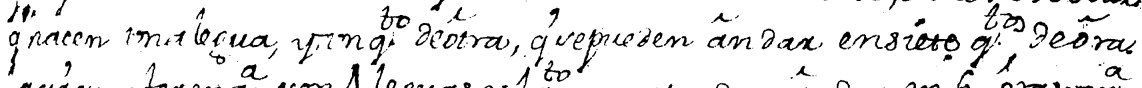

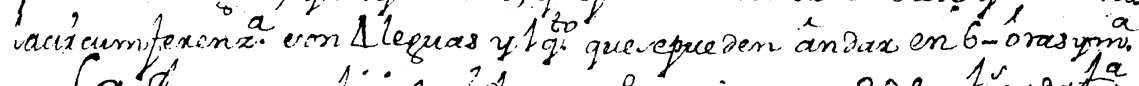

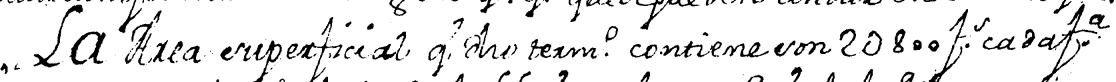

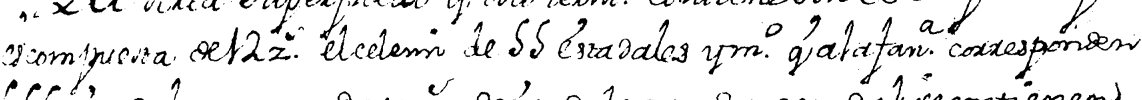

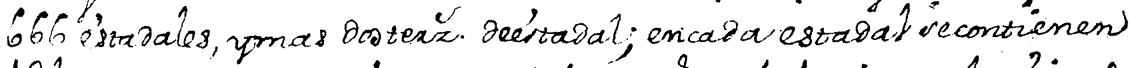

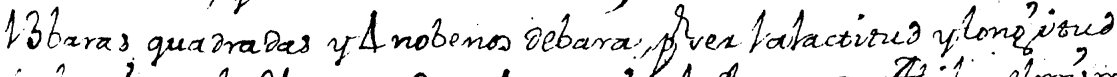

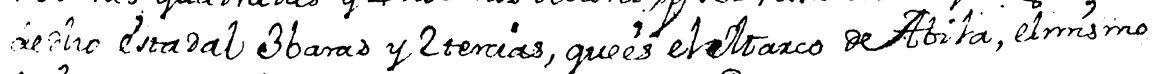

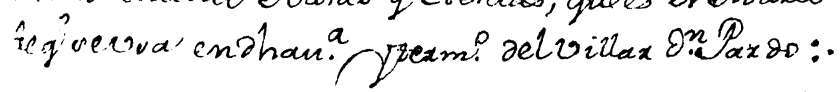

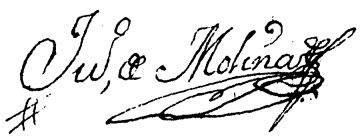

Mapa original de Villardompardo (Jaén), levantado por el geómetra Juan de

Molina, conservado entre las autos y diligencias de la operación (AHPJ). 


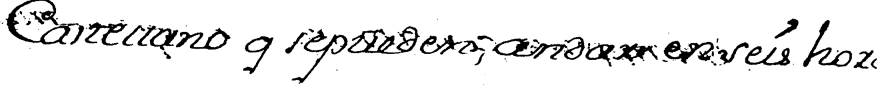

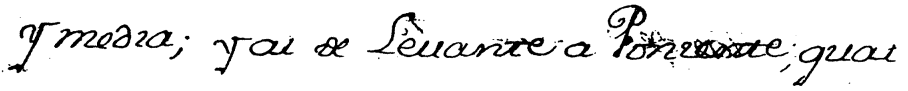

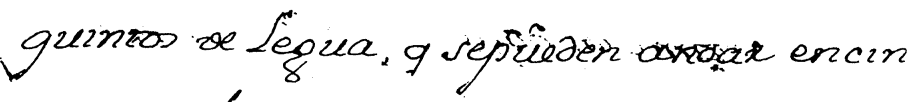

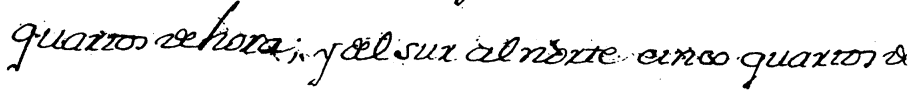

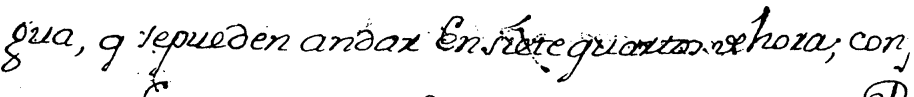

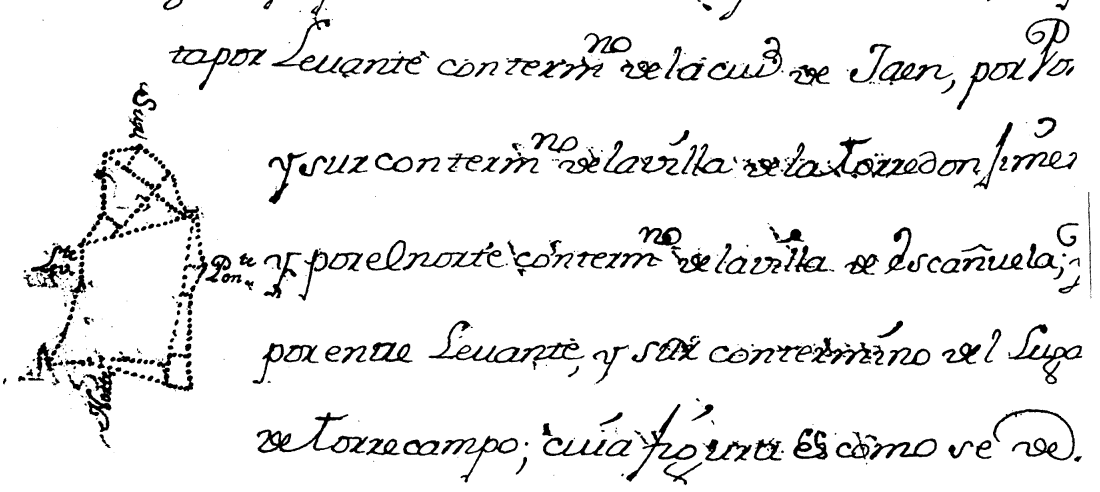

muessa.

49

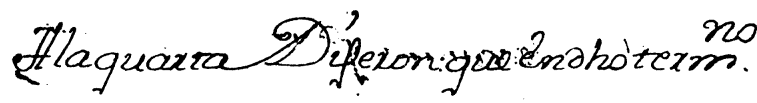
veâllan áfexwes expecres : viziza we secano, 9.pxoauzex un futy allano win yntexmis

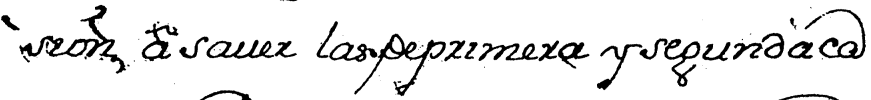

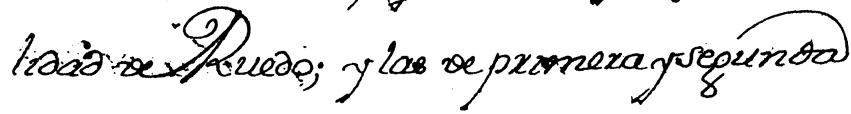

Página de las Respuestas Generales originales de Villardompardo en la que se incluye el mapa del término (AHPJ).

$$
-253-
$$


quaxtar se oxa; y teb CCox al noxter

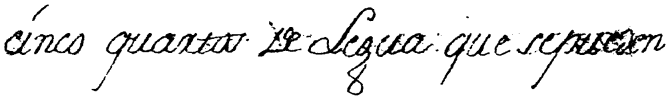

andax en sette quaxtos sroxa, Cos.

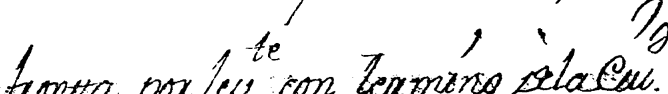

frontta pox Lew con Zexmino pelaceu.

sitaen, dox Lon, y sux contexm.

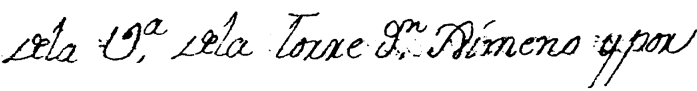

el Poxtu con Texmonosita Millaze

Encanuela y parentue devity cuxicon

Texmino tel alugax we loxxe Caxs-

po: Cuya fóuxa es Comore Demu-

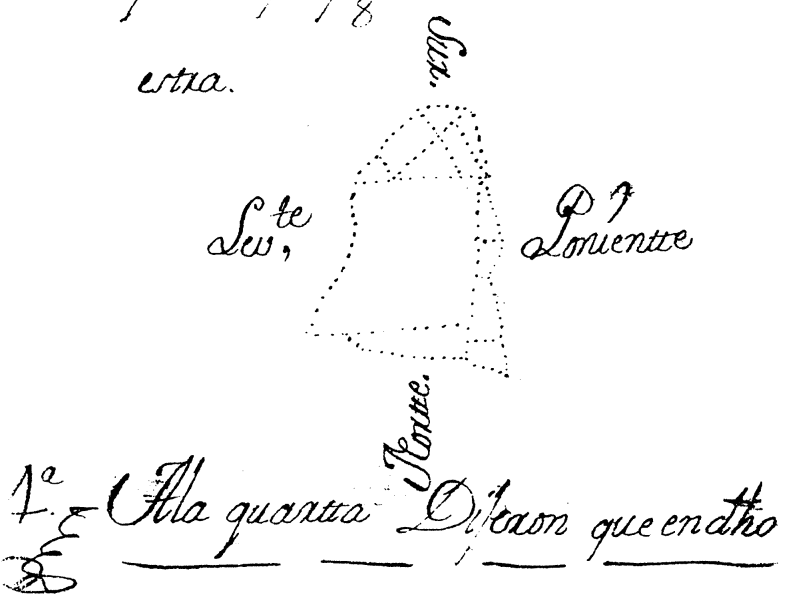

Página de la copia de las Respuestas Generales de Villardompardo en la que se incluye el mapa del término, custodiadas en el Archivo General de Simancas. 
dibujado en el margen de las Respuestas originales y el de la copia de dichas Respuestas custodiada en el Archivo General de Simancas. En estos tres mapas, que se reproducen en el presente trabajo, puede apreciarse el proceso de simplificación y de pérdida de información que se produce en las sucesivas copias del mapa, al pasar de un nivel documental a otro.

La explicación de las diferencias observadas entre los mapas de las Respuestas originales y de las copias y entre las distintas provincias estriba probablemente en el hecho de que, estando ordenado que las copias de las Respuestas debían hacerse «a la letra», debió interpretarse por algunos responsables provinciales que tal orden no afectaba al mapa de los términos, que redujeron a su mínima expresión: el trazado del perímetro y, a veces, también a la colocación de sus puntos cardinales, siendo así que en muchos mapas originales figuran los ríos, la división del término en hojas de cultivo, la posición del núcleo habitado y de las casas dispersas, la de los molinos y batanes, las ermitas, el nombre y límites de los pagos, los montes, las dehesas boyales, la red caminera, los puentes y barcas, minas, ledanías y términos comuneros, etc. Son ejemplos, el mapa de Toro, que representa sus múltiples despoblados y pagos, el de El Bodón, pueblo salmantino cuyo término aparecía dividido no en tres sino en cuatro hojas de cultivo, a más de la dehesa boyal, o el de Almazán, pueblo soriano cuyo caserío pugna por romper el estrecho cerco de sus murallas. En esta línea, y como ejemplo, merece una mención especial, por la riqueza de la información que recoge, a pesar de la simplicidad de su trazado, el mapa del pueblo jiennense de Quesada incluido en las Respuestas originales. En él, su autor representa de manera muy pormenorizada los ríos que recorren el término, indicando incluso con la anchura del trazo la importancia de los mismos: el que identifican como Guadiana (en realidad el Guadiana Menor) como río principal que, literalmente, divide el término en dos partes, y varios de sus afluentes, identificando el río de Tíscar, que parece perder ese nombre, así como su condición de tal, al acercarse a la confluencia con el Guadiana, pasando a denominarse «roio molinos». Recoge también otros dos afluentes que bajan de la sierra por poniente y cuyos nombres no se incluyen. $\mathrm{Al}$ este, abriéndose paso entre el escarpado relieve de la sierra, se vislumbran el Guadalquivir y varios ríos de importancia mucho menor, que no se identifican, probablemente porque vierten su aguas en los términos colindantes de Cazorla y Pozo Alcón. Asimismo, identifican clara- 


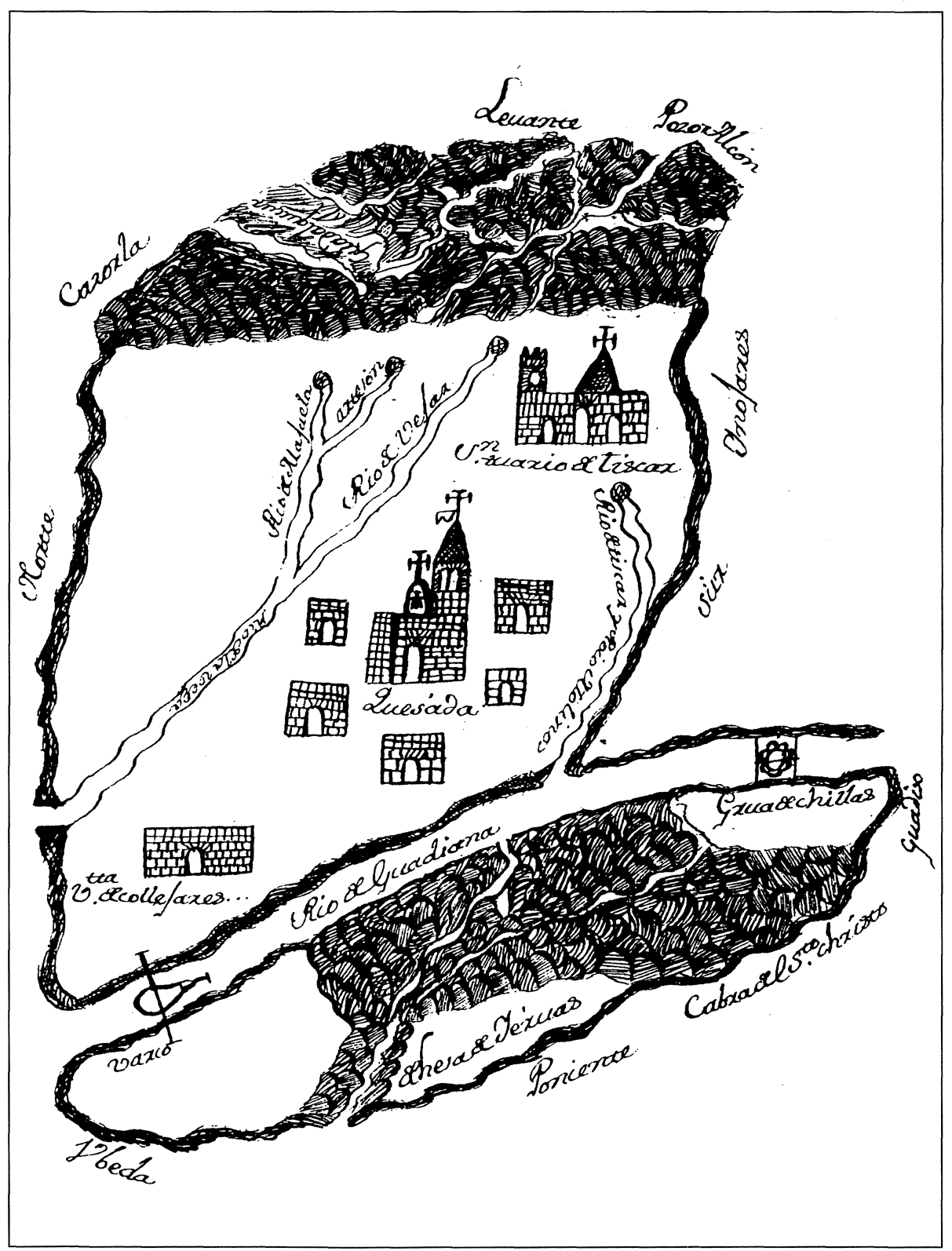

Mapa de Quesada (Jaén), incluido en las Respuestas Generales originales de la villa (AHPJ). 


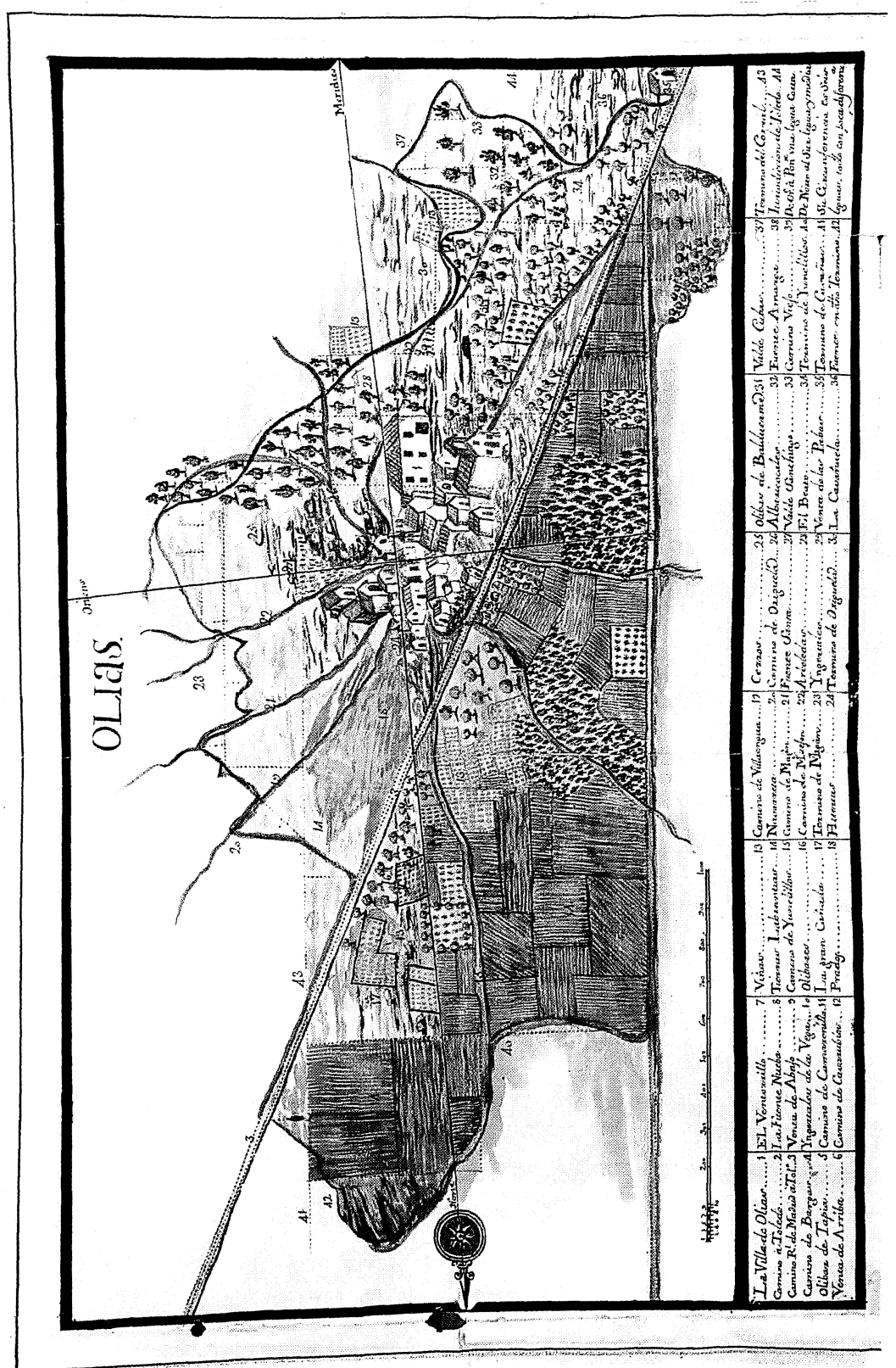




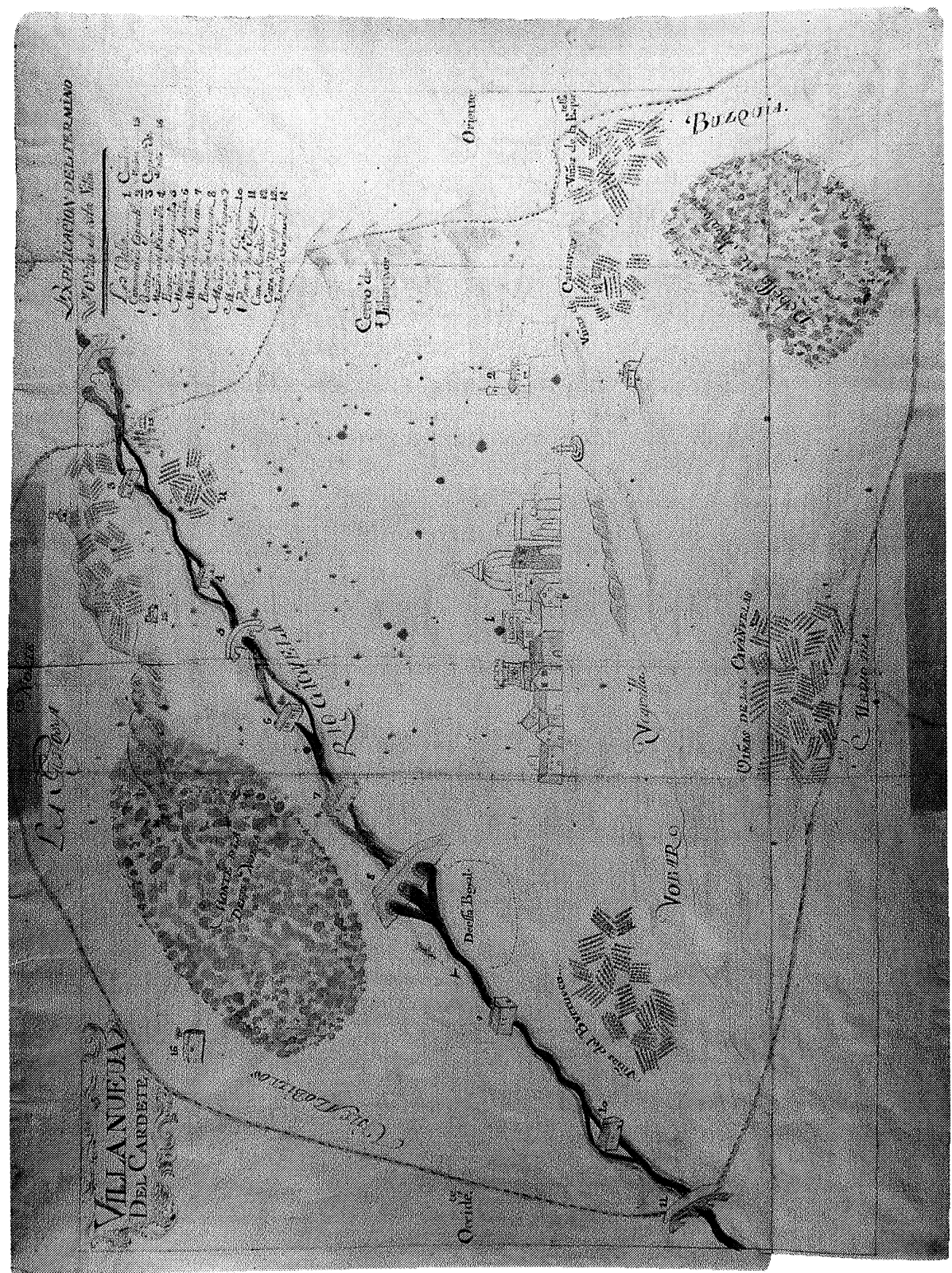




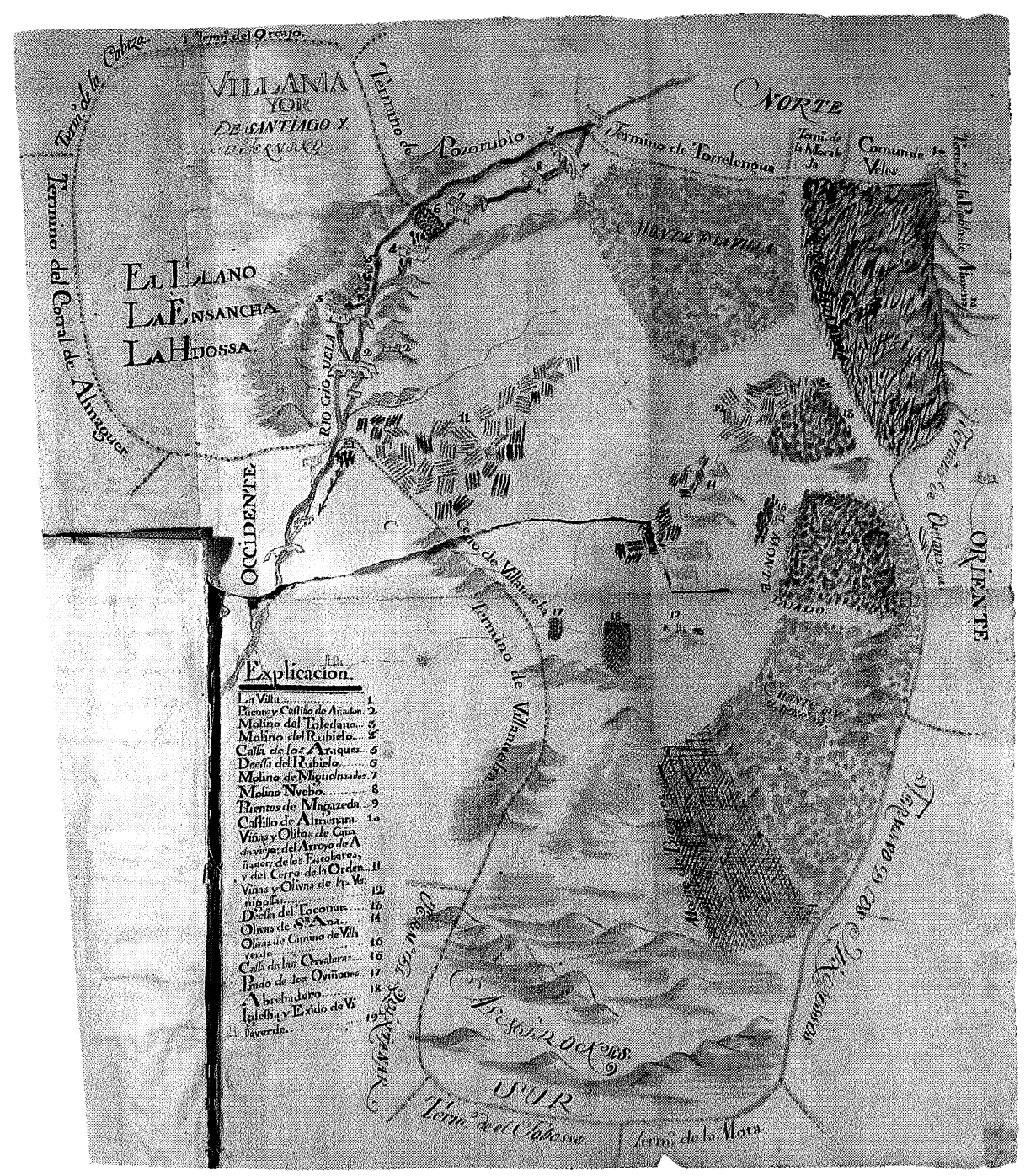

En estas páginas a color: Mapas de Olías, localidad de la provincia de Toledo (AHPT); Villanueva del Cardete, de La Mancha (AHPT), Villamayor de Santiago, de La Mancha (AHPCR); El Bodón, de Salamanca (AGS); Almazán, de Soria (AHPS); Tirateafuera, de La Mancha (AHPCR); Dúrcal, de Granada (AHPG), y Almadén, de La Mancha AHPCR). (Láminas proporcionadas por la autora.) 


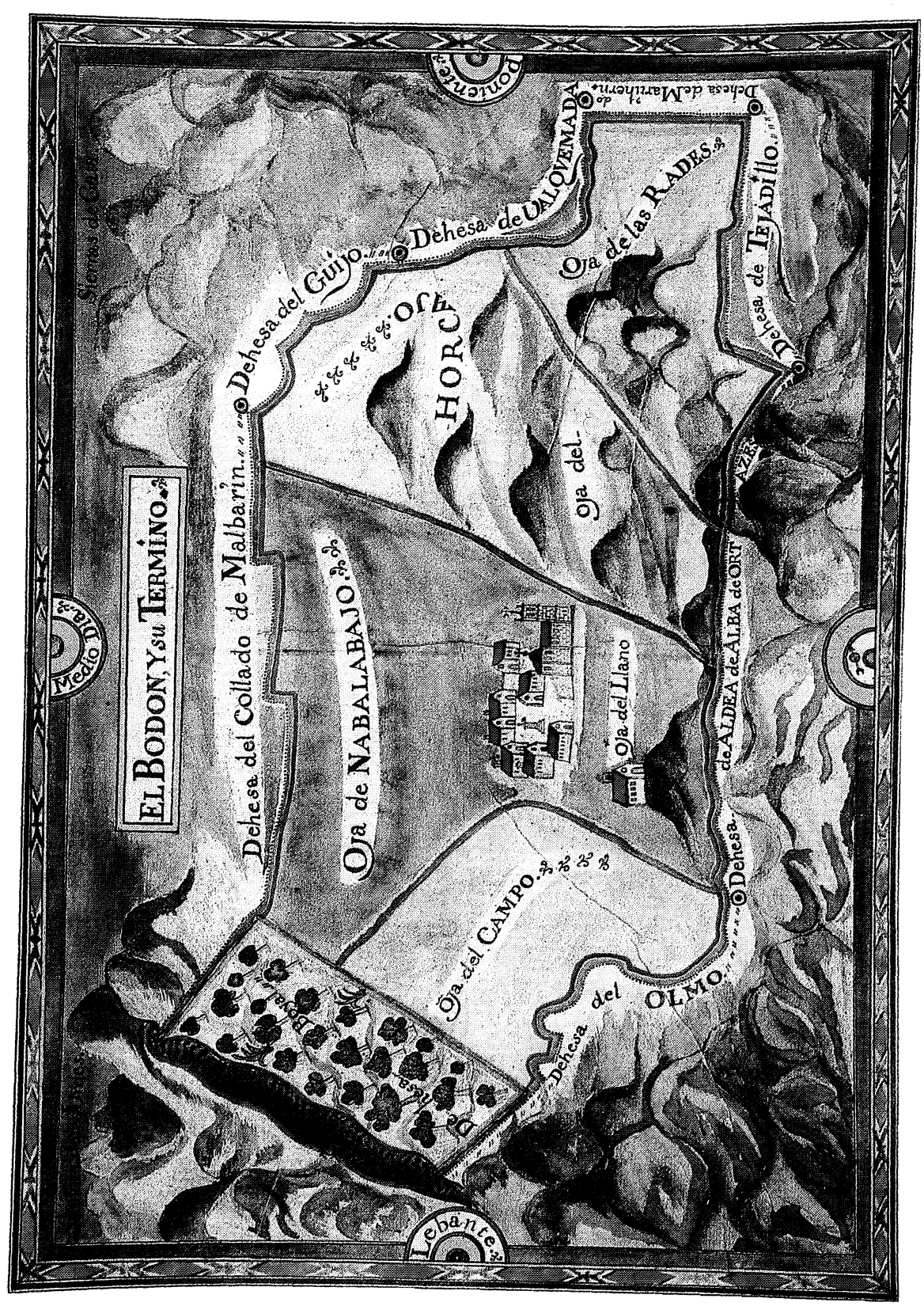




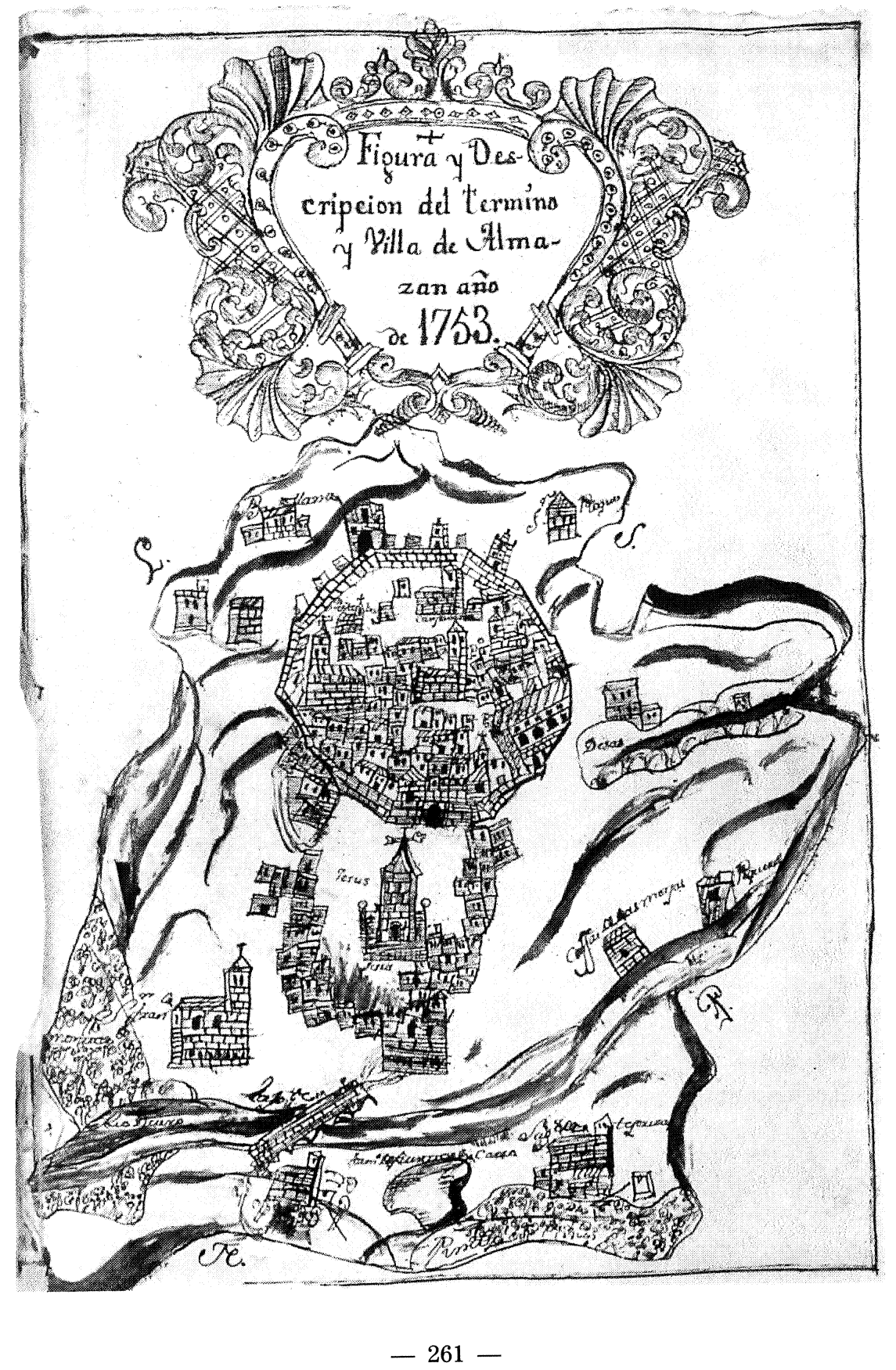




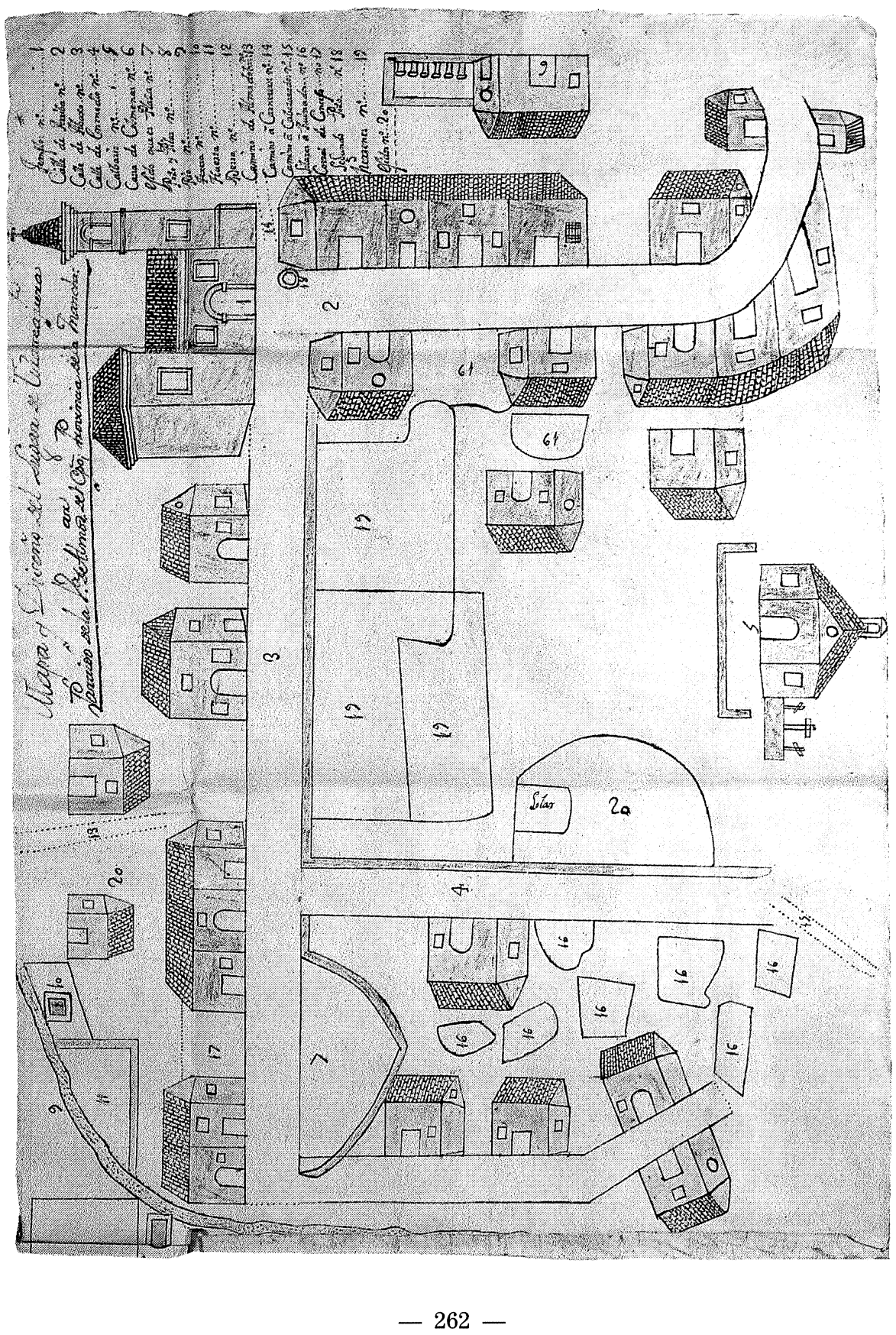




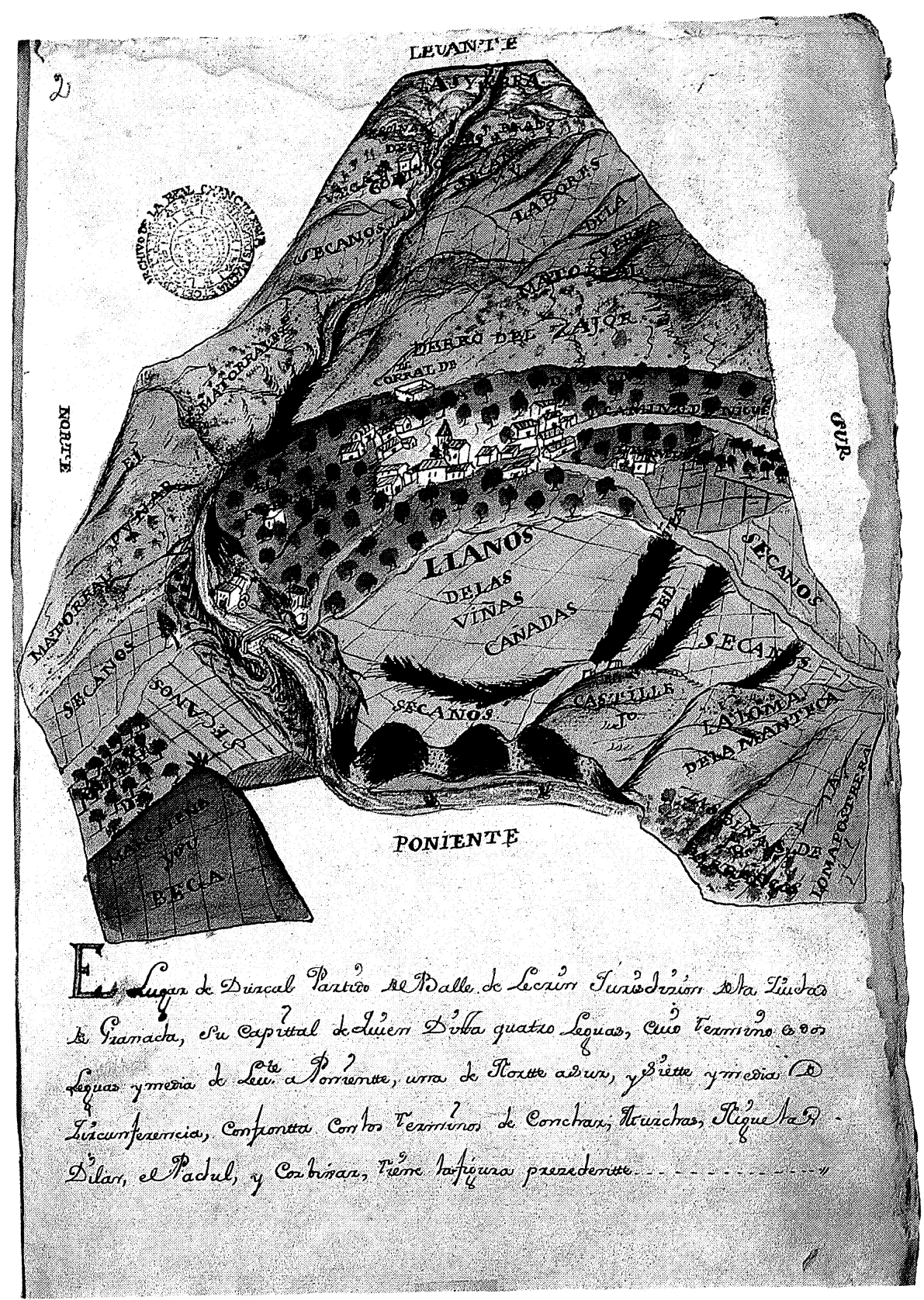




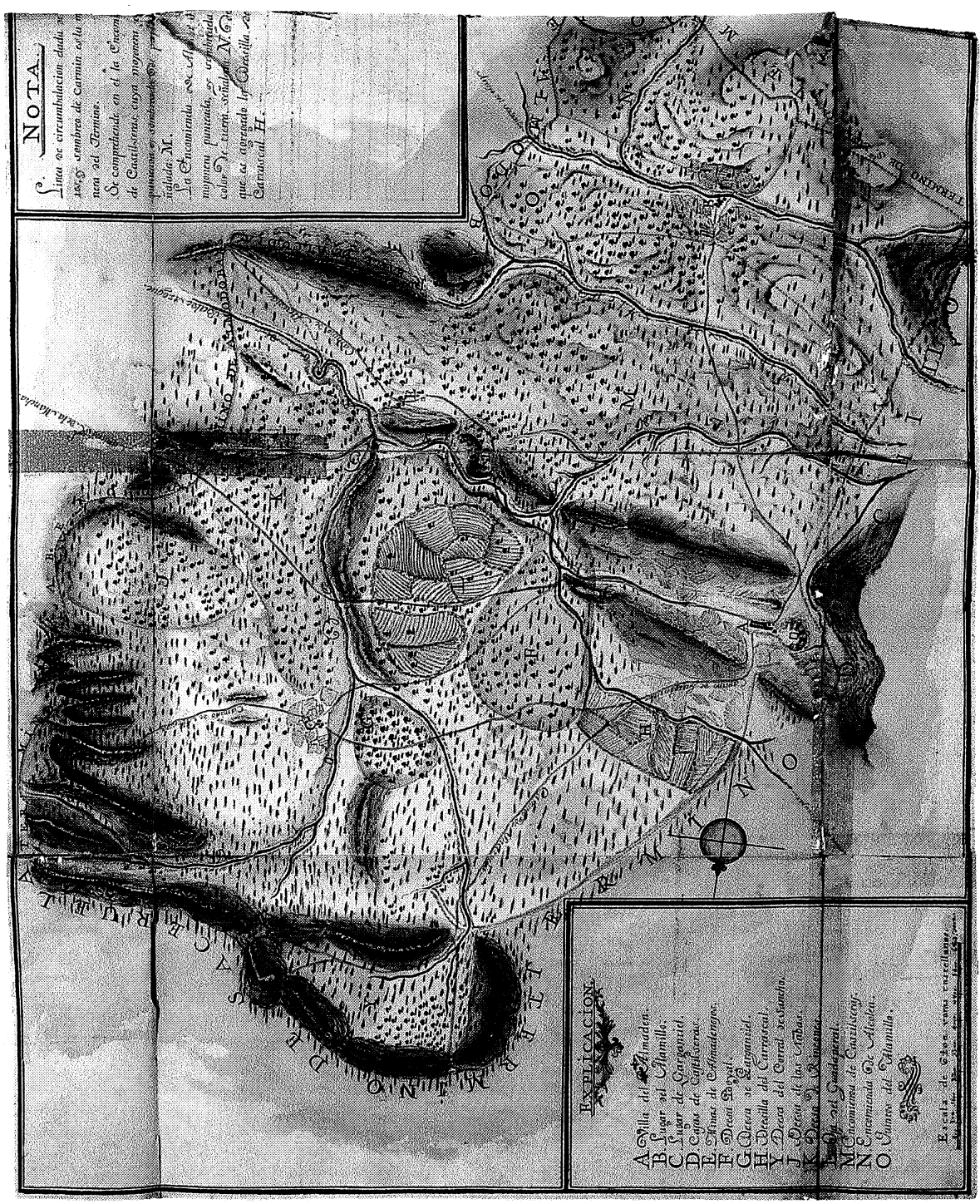


mente el complejo hidrológico formado por los ríos «Majuela, Artejón, Véjar», que acaban dando lugar al «río de la vega». Otros elementos referenciales importantes para la vida de la villa aparecen también en el mapa: el caserío de la misma, muy simplificado, con su iglesia, de mayor tamaño que las casas y representada con una torre de mayor altura que el campanario, con una sola campana, el santuario de Tíscar, la venta «de Collejares», la «dehesa de Yervas» y, sobre el Guadiana, una barca para cruzarlo y una grua, que denominan «de Chillas». Además, mediante un elementalísimo, pero eficaz, sistema de sombreado representan la escarpada topografía de las sierras.

Otros ejemplos de riqueza informativa, además de belleza gráfica, son también los mapas de Chite y Talará, Dólar, Dúrcal, Nigüelas, Barranco de Poqueira (Granada), Olías (Toledo), Astudillo (Burgos entonces, Palencia hoy), Tirateafuera, Saceruela, Valdepeñas (La Mancha), Avilés (León-Asturias), Gascones (Madrid hoy, Guadalajara entonces) o el de las Quintanillas (Burgos) ${ }^{3}$. Caso muy especial es el de Almadén (La Mancha), realizado con gran calidad técnica, probablemente por encontrarse en su término las minas de azogue que llevan su nombre y que eran gestionadas directamente por la Corona y «laboradas» por penados.

Pues bien, en ese proceso de simplificación de la documentación original a la copia se da incluso el caso de provincias en las que ni siquiera se dibuja el esbozo del término, como es el caso de Murcia o Galicia.

Podemos afirmar, pues, que la diversidad será el principio general, ya que, frente a provincias como La Mancha, Guadalajara, Jaén, Granada, León-Asturias, etc., que realizan en muchos pueblos mapas con información abundante, a veces incluso a toda página, otras reducirán todo a un mero perfil, y ello tanto en los originales como en las copias. Cupo mucha responsabilidad en esto a la propia Junta y, en especial, a su experto, el marqués de Puertonuevo, que no solamente no exigió des-

${ }^{3}$ Los mapas de Toro, Astudillo y Las Quintanillas, junto con algunos de la provincia de Burgos, aparecen publicados en C. CAMARERo (1989): Burgos y el Catastro de Ensenada. Burgos, Caja de Ahorros Municipal, págs. 127, 79 y 155. Algunos mapas del Catastro de Granada aparecen recogidos en GALlEGo RocA, F.J. (1987): Morfología urbana de las poblaciones del reino de Granada a través del Catastro del Marqués de la Ensenada. Granada, Diputación Provincial, y en Titos MARTínez, M. y PIÑAR SAMOS, J. (1995): Álbum cartográfico de Sierra Nevada (1606-1936). Granada, Fundación Caja de Granada, págs. 94116. Algunos mapas del catastro soriano han sido reproducidos en el número monográfico de la revista Arevacón dedicado a Soria en el Antiguo Régimen, y el de Gascones, en GRUPo'73 (1973): La economía del Antiguo Régimen. El Señorío de Buitrago. Madrid, UAM, pág. 13. 


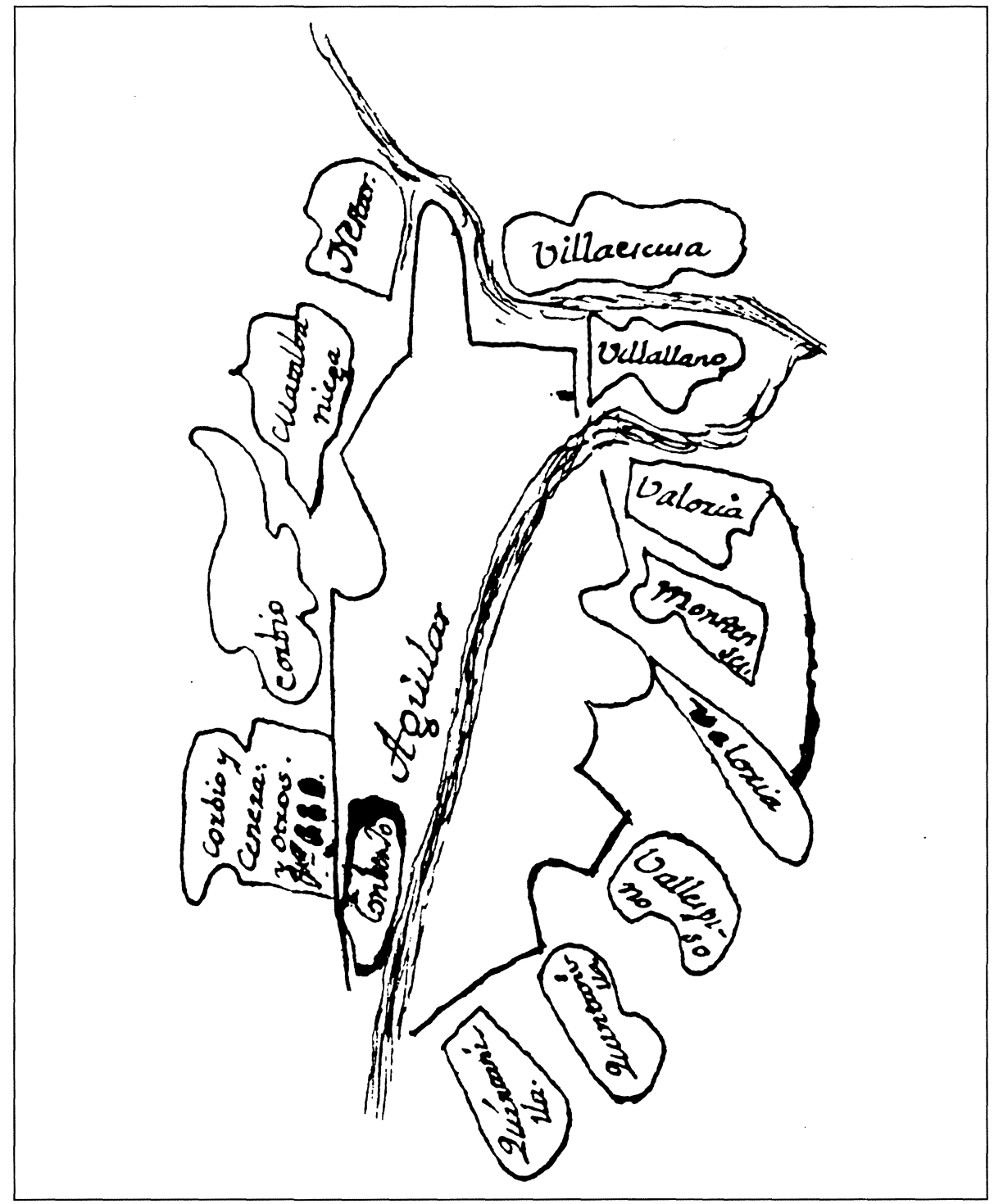

Mapa de Aguilar de Campóo (Palencia) incluido en las Respuestas Generales originales, en el que se representan los términos comuneros que la villa tiene con otros pueblos, la posición de uno de sus dos conventos, probablemente el de Santa María la Real, y el río Pisuerga. Obsérvese la importancia concedida en la representación al río (AHPP). 


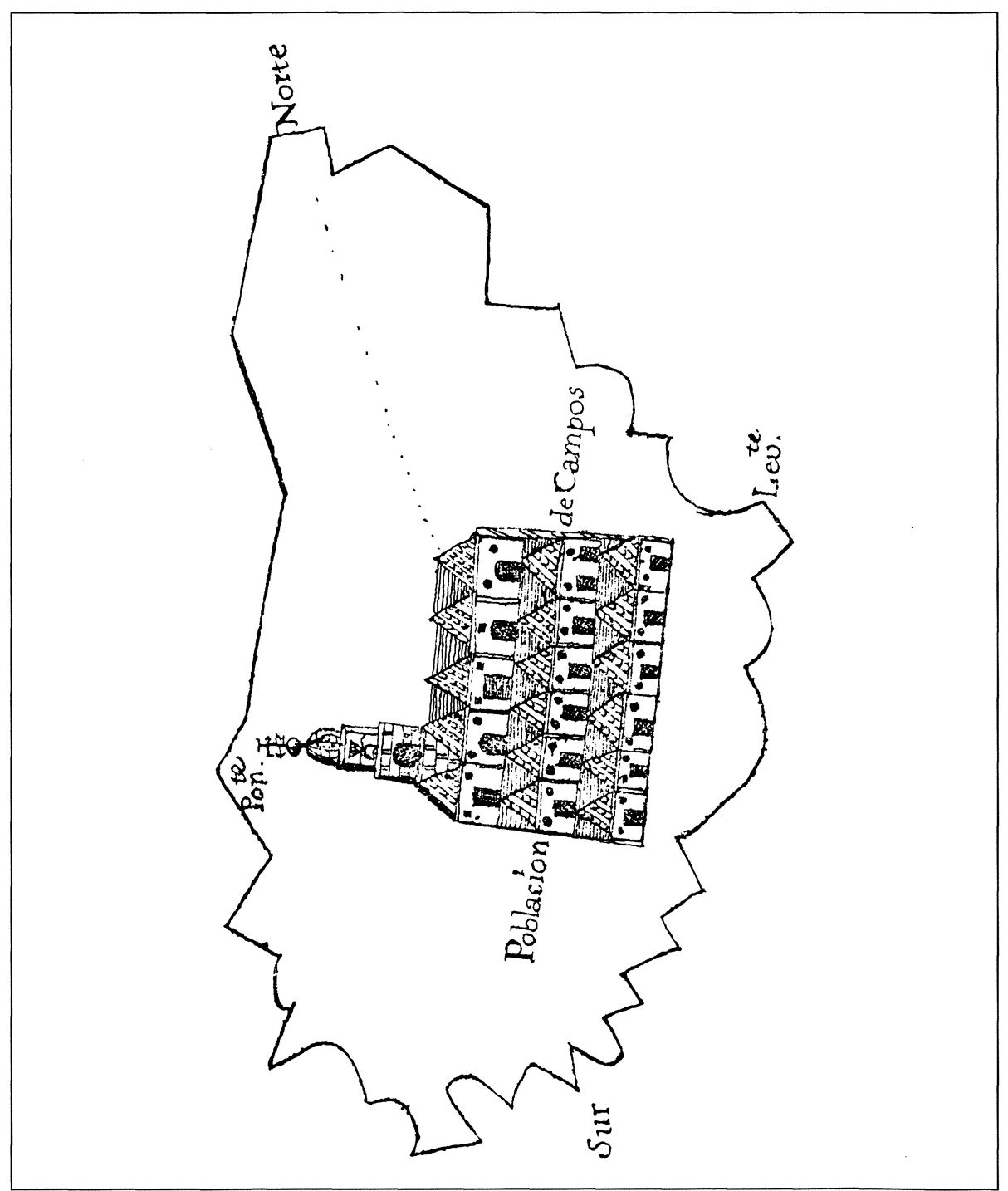

Mapa de Población de Campos (Palencia) incluido en las Respuestas Generales originales. El término de esta población, como el de la gran mayoría de las localidades palentinas se midió. La zona de la Tierra de Campos fue una de las más conflictivas en las averiguaciones catastrales (AHPP). (Vid. CAMARERO BULLON, C. (1990): "El Catastro de Ensenada en Palencia: una averiguación conflictiva», en Actas del II Congreso de Historia de Palencia, tomo III, vol. I, págs. 251-268.) 


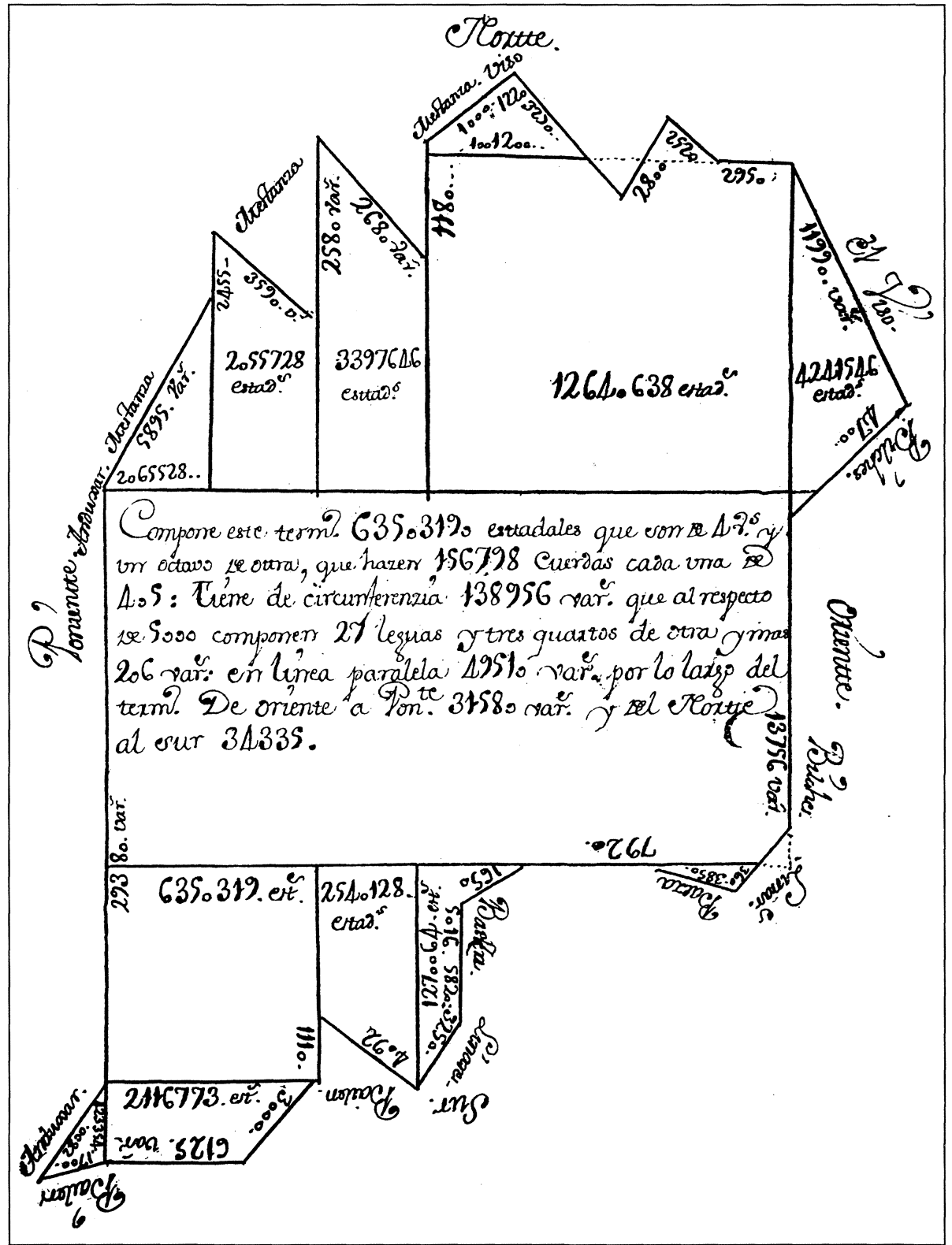

Mapas de Baños de la Encina (arriba) y de Canena incluidos en las Respuestas originales de ambos pueblos jiennenses. Sus términos se midieron (AHPJ). 


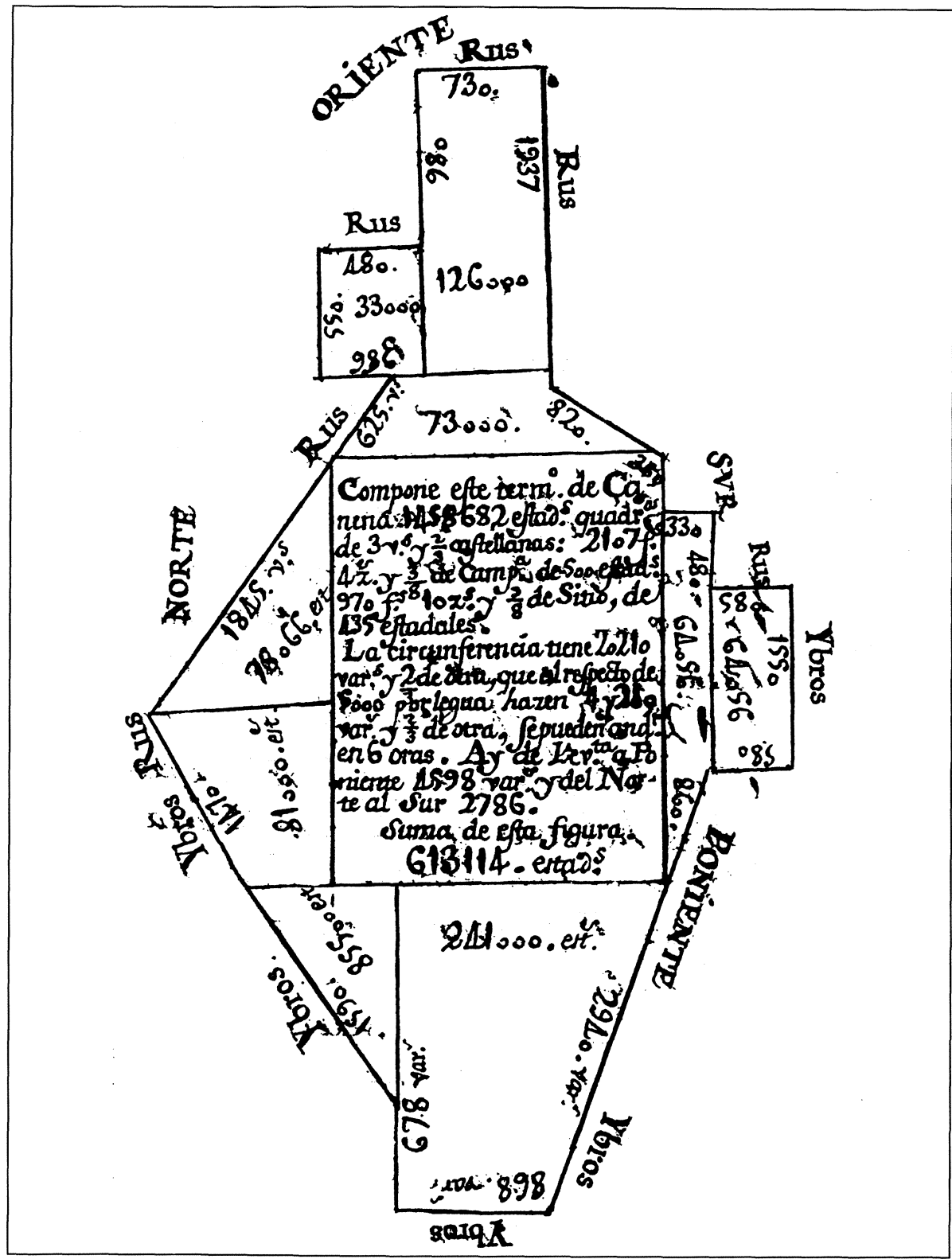


de el primer momento una realización cartográfica prolija sino que desanimó a quienes con especial celo lo intentaron. Buen ejemplo de ello es lo sucedido con el subdelegado Agustín Sebastián Ortiz, que operó el pueblo madrileño de Fuenlabrada, primera operación de la provincia. Sebastián elabora un mapa, a gran formato, en el que representa a escala todas las parcelas, incluyendo, dice, «las especies y figuras de las tierras, así calvas, como viñas, retamares, prados y barrancos», insertando una escala geométrica suelta para medirlas, lo que, según el autor, hacía innecesario representar en otros documentos catastrales las figuras. Sin embargo, cuando lo examina el experto de la Junta, dice: «Que en adelante no realice mapas de los términos, pues ello atrasa la obra» ${ }^{4}$.

A pesar de todo, fueron varias las provincias en las que se procedió a la medición rigurosa de todos o de muy buena parte de los términos: León, La Mancha, Jaén, Palencia, Toledo y Valladolid. En la de La Mancha, el término de Torralba de Calatrava, por ejemplo, resulta exactamente con 14.237 cuerdas, «incluyendo barrancas, vertientes y baldios». En Valladolid se miden en algunos casos los términos entre otros fines para disponer de un elemento de verificación de las declaraciones. Así, en Tordesillas ${ }^{5}$, al constatar el intendente una notable diferencia entre la suma de las tierras individuales y el total del término resultante de la medición, procede a revisar todo, llegando a la conclusión de que los agrimensores habían medido incluso los eriales incultos que había dentro de tierras de pan llevar, de viña y de otros frutos, con senderos y otros huecos, por haber tirado el compás en la medición de pagos y no pieza por pieza, mientras los labradores sólo habían declarado la tierra fructífera. Al conocer la Junta tales diferencias, le dice al intendente: «lo que importa es saber la verdarera consistencia de todo género de bienes, industrias y utilidades, debiendo sujetarse al juicio de agrimensores y peritos, por quedar siempre a los dueños y vecinos la libertad de pedir, en caso de agravio, la medición rigurosa de las tierras, debiendo prevenir a los peritos que en la computazión de medidas de pagos o territorios tengan presentes los senderos, barrancos, vertientes de aguas, pinares, bal-

\footnotetext{
${ }^{4}$ Véase CAMARERo, C. (1990): Fuenlabrada en 1751 según las Respuestas Generales del Catastro de Ensenada. Madrid, Centro de Gestión Catastral y Cooperación Tributaria y Tabapress, Colección «Alcabala del Viento», . $^{\circ} 2$.

${ }^{5}$ Véase VVAA (1994): Tordesillas en 1751 según las Respuestas Generales del Catastro de Ensenada. Madrid, Centro de Gestión Catastral y Cooperación Tributaria y Tabapress, Colección «Alcabala del Viento», n. ${ }^{\circ} 16$.
} 
díos que estén mezclados con tierras de cultivo a fin que el número de medidas se ajuste a lo efectivo y verdadero». Es decir, no se renuncia a la exactitud, a pesar de haber rebajado el nivel de los técnicos medidores. Pero esto no se puso en práctica en muchos casos, limitándose los capitulares que responden al Interrogatorio a realizar un trazado más o menos fiel del perímetro. Sin duda contribuyó a ello la norma de que la figura fuese trazada en el margen de las respuestas, con lo que el ancho máximo disponible no rebasaba los cinco centímetros, si bien es cierto que algunas audiencias no cumplieron la norma y utilizaron páginas completas, como ocurrió con las que operaron algunos pueblos de Granada, Sevilla, Jaén o La Mancha.

En cuanto a la figura de las tierras, el principal problema se derivó del poco convencimiento de los intendentes acerca de su utilidad, ya por considerar que las figuras serían mudables en el futuro (compraventas, herencias, intercambios), ya por la escasa precisión y fidelidad de las representaciones que cabía conseguir. A ello se añadía el tiempo necesario que, agregado al empleado en las restantes diligencias, dilataría demasiado la obra. En otros casos se alegaba la dificultad de representar tierras con formas muy complejas, o en medio de las cuales existían accidentes que complicaban la representación y la descripción, sobre todo por resultar muy prolijo dar todas las confrontaciones o linderos. El intendente de Valladolid, Manuel Francisco Pinel, advertía sobre la operación de Tordesillas que «ha omitido la figura de cada pieza de tierra y las afrontaciones de los cuatro aires, pues ha juzgado ympracticable estas formalidades en un término tan dilatado y por la casi ninguna separación que tienen las tierras entre sí por los quebrados y desfiladeros que hay, y por los bosques o dehesas de pinares que los dividen». Y el de Guadalajara advertía sobre las modificaciones que iban experimentando las figuras trazadas en los memoriales o en los cuadernos de cotejo en su proceso de traslación a los diversos documentos catastrales, puesto que «la primera vez que las dibujan en borradores es sobre la rodilla, que se copian después quatro o más veces». A la falta de precisión se añadía la demora que tal orden implicaba, pues no se podía salir al campo con lluvia, «pues si llueve no se puede trabajar sobre el papel», decía el de León, Agustín Giraldez y Ordóñez, por lo que era preciso optar entre la brevedad del catastro y la figuración presencial de las tierras. La Junta, ante manifestaciones tan unánimes, fue contestando a todos que no podía excusar tal labor, pero que «bas- 
tará que se noten del modo que se sugetan a la vista», como diría al intendente de Palencia.

Pero incluso ese tipo de representación será considerado de muy difícil cumplimiento en los términos multiparcelados. Obviamente, las mayores dificultades se hallaron en Galicia, Burgos, Asturias y León. El intendente de esta provincia, antes incluso de dar comienzo al catastro, empieza a referirse en sus cartas a algo que será una de sus constantes: el tamaño y forma de las tierras («que apenas tienen 20 pasos y aun están atravesadas por una punta de otro dueño»), por lo que, decía, en su provincia «se necesitará mucho geómetra para figurarlas y mucho tiempo para descrivirlas». Sugiere no dibujar las tierras, eliminar las confrontaciones, y no pasar las tierras a los Libros de lo real, dejándolas sólo en los Memoriales; razonaba diciendo que era obligado tener en cuenta que el catastro se iba a quedar viejo enseguida, «pues la heredad que oy posee Pedro, con figura triangular, muerto éste y dividida entre sus hijos, echan un surco u otros mojones, o un dueño de la vecina compra la contigua, haze de dos una y pierden la figura». La Junta, consecuente con sus planteamientos, se limita a decirle «que se arregle a la Ynstrucción en todo», y que las tierras «las ponga como aparezcan a la vista, azercándose todo lo posible a la verdad».

Meses más tarde, la Junta se interesa por la marcha de la averiguación de León, concretamente de su primera operación, la de Villamañán, oportunidad que aprovecha el intendente para volver a lamentarse del trabajo que da el microfundio y pedir que se le autorice a que únicamente se señale en qué pago está cada tierra. Dice que calcula habrá en ese término más de 10.000 piezas de tierras labrantías y por encima de 15.000 de yerma, y que en dos meses llevan figuradas y descritas los peritos solo 2.000 , pues solo 20 declarantes de los 600 existentes habían puesto las confrontaciones, alegando los demás no saber qué era eso. Y por si la Junta consideraba como exageraciones del intendente tales datos, le remite copia de tres memoriales, todos ellos del grupo de los veinte que sabían qué era eso de las confrontaciones o aires: la Fábrica de la Iglesia, el cura de la Villa y la Cofradía de Ntra. Sra. del Rosario. No es posible ofrecer aquí su transcripción íntegra por su proligidad; sin embargo, un ejemplo puede ser significativo: «una tierra a do llaman el Quarto del camino que va para Villamayor azia el río y tiene 2 mangas azia dicha parte, y otra hacia dicha villa, que toda ella con sus mangas hace mil y trescientos treinta y dos palos y entre las mangas se entra 
una tierra de Juan [...], y hazia Benamariel tiene un codito y cabecea hacia el río con tierra de la Iglesia de dicha Villa y del Concurso de Juan Manuel Villarroel...».

Si esto sucedía en León, imagínese Galicia. Balthasar de Rojas Zorrilla, subdelegado que operó el Coto de Sayar, al finalizar da cuenta de haber empleado tres meses, gastado 9.000 reales y escrito 2.060 hojas («volumen espantoso») sólo en el Libro de lo real de legos, «todo ello por la precisión de descrivir con todas sus circunstancias las minutísimas partidillas en que está dividida en este Pays la tierra, interpolada y confusa entre diversos poseedores, de suerte que en Castilla en un monte se pone una fanega y aqui requiere 384 asientos, porque en otras tantas partes suele por lo regular estar dispersa la porzión de quatro ferrados, que es su equivalente, y asi se multiplican con la repetición de tanto requisito de lindes, cavidas, especies, sitios, nombres, figuras, etcétera».

Por ello, cuando se acaba la averiguación de Galicia, calificada como la Babel del catastro, uno de sus dos máximos responsables, el comisionado Francisco Javier García Serón, se mostrará feliz por haber conseguido lo que en algún momento le debió parecer un imposible, al topar con lugares donde no había ni vecindarios «ni libros de nada», ni límites entre las feligresías: «Insensiblemente - dice-los fuimos apurando, y liquidando», consiguiendo con la Única «lo que hasta aora en este Reyno no se ha podido conseguir, ya sea por recelo, desidia o pereza»; desde ahora, proclama, «se sabrá aun del más escondido individuo, y de quántas tierras, casas, ganados, y demás de que se compone, pisa y habita este pays». Realmente debió quedar impresionado de «tan basto, esparzido y disperso reyno, todo poblado pero sin forma, y todo cultivado, y con más de veinte millones de divididos ferrados, que quasi nezesitan de otros tantos asientos», un hombre originario del sureste peninsular como era Serón.

El hecho es que, a pesar de las dificultades, dos documentos catastrales recogen las figuras de los millones de parcelas catastradas: los $\mathrm{Me}$ moriales y los Libros de lo real, cuya conservación es irregular. Frente a provincias que los conservan íntegros o casi íntegros, como Burgos, Jaén, Toledo, Segovia, Palencia o Guadalajara, en otras están total o casi totalmente perdidos, como son los casos de Sevilla, Toro, Madrid, Cuenca, Murcia o Extremadura. Queda solamente una esperanza remota: que se conserven en algunos ayuntamientos las copias de los Libros de 


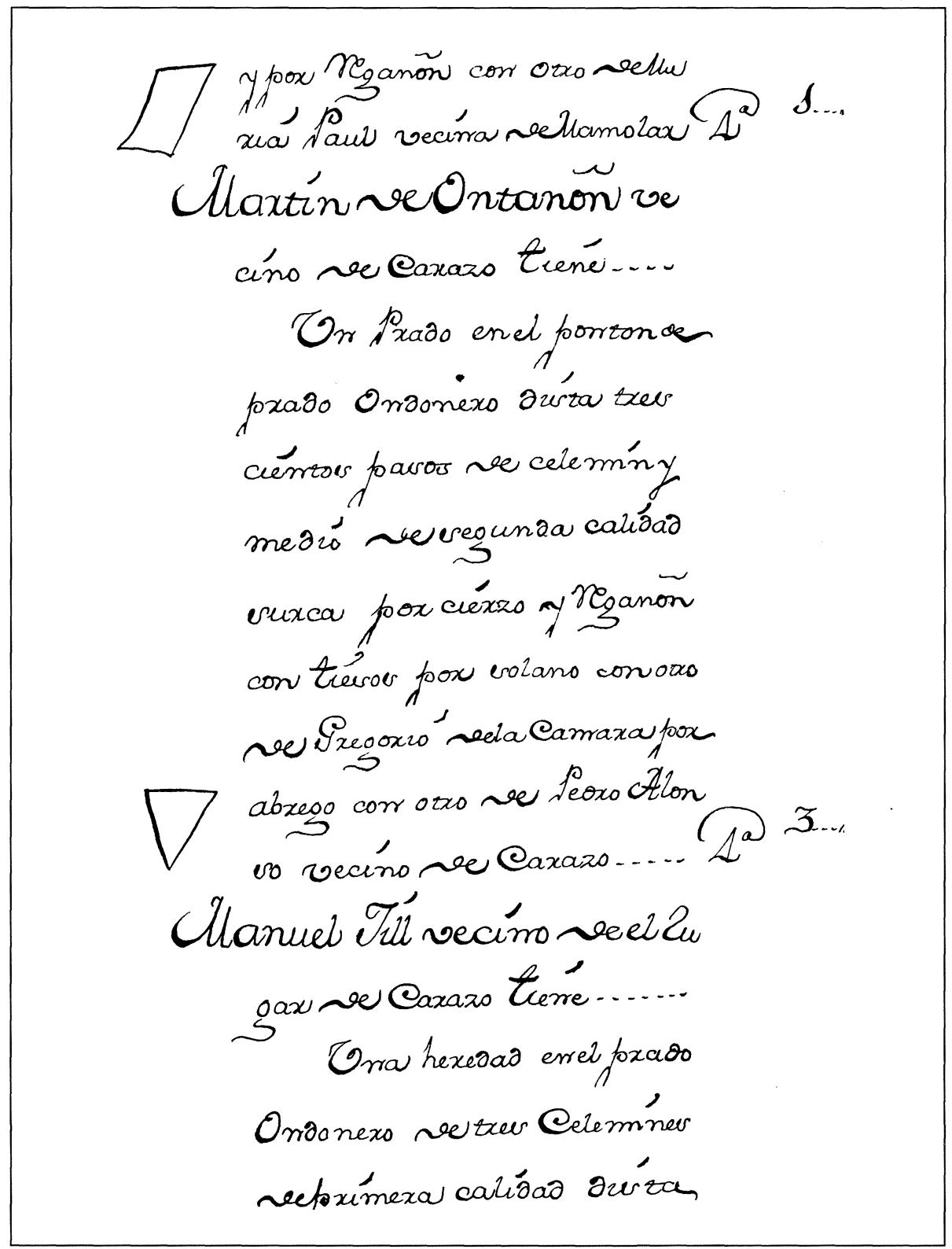

Doble página del Libro de lo real de legos del lugar de Gete (Burgos) (ADB). 


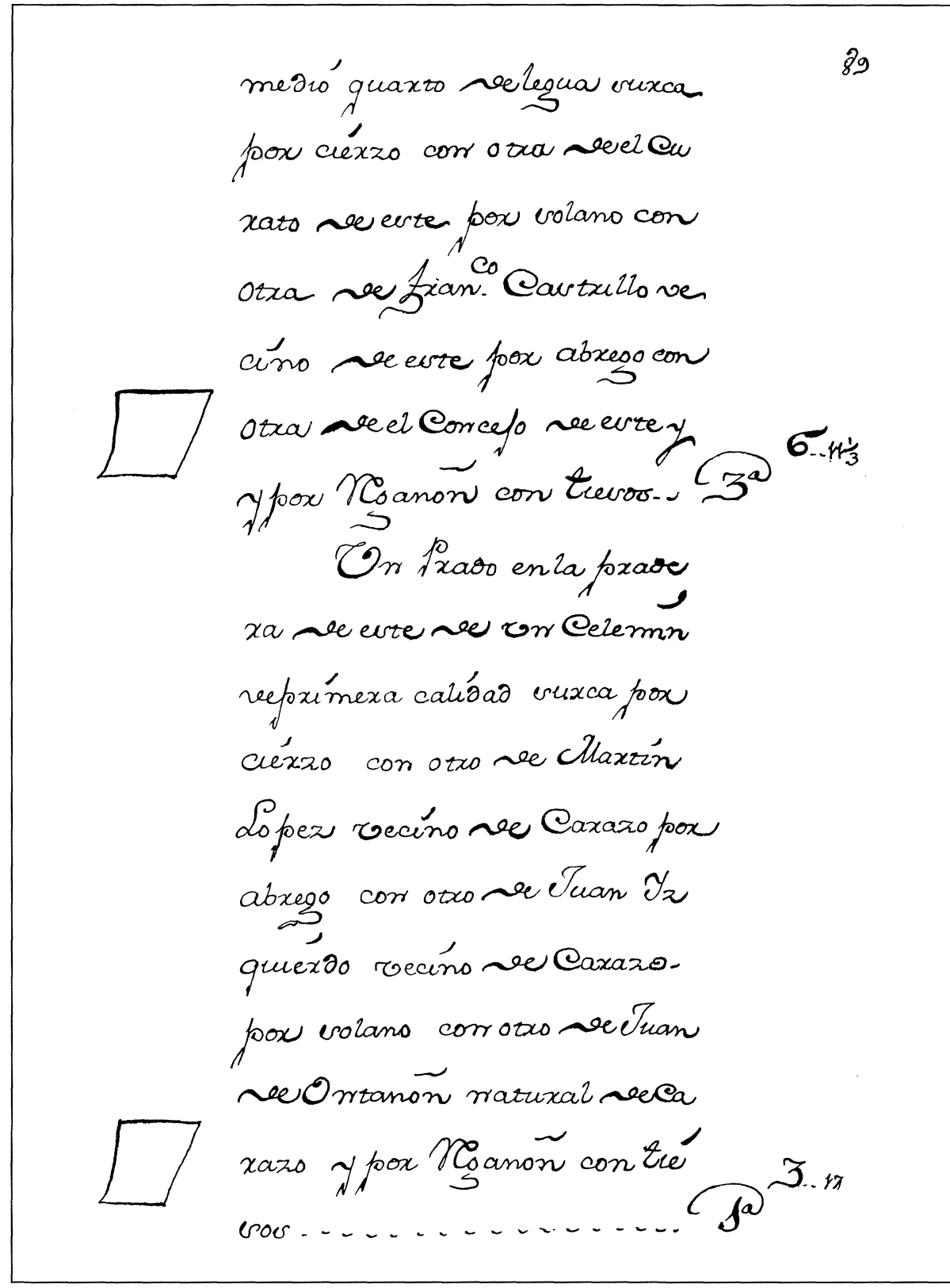




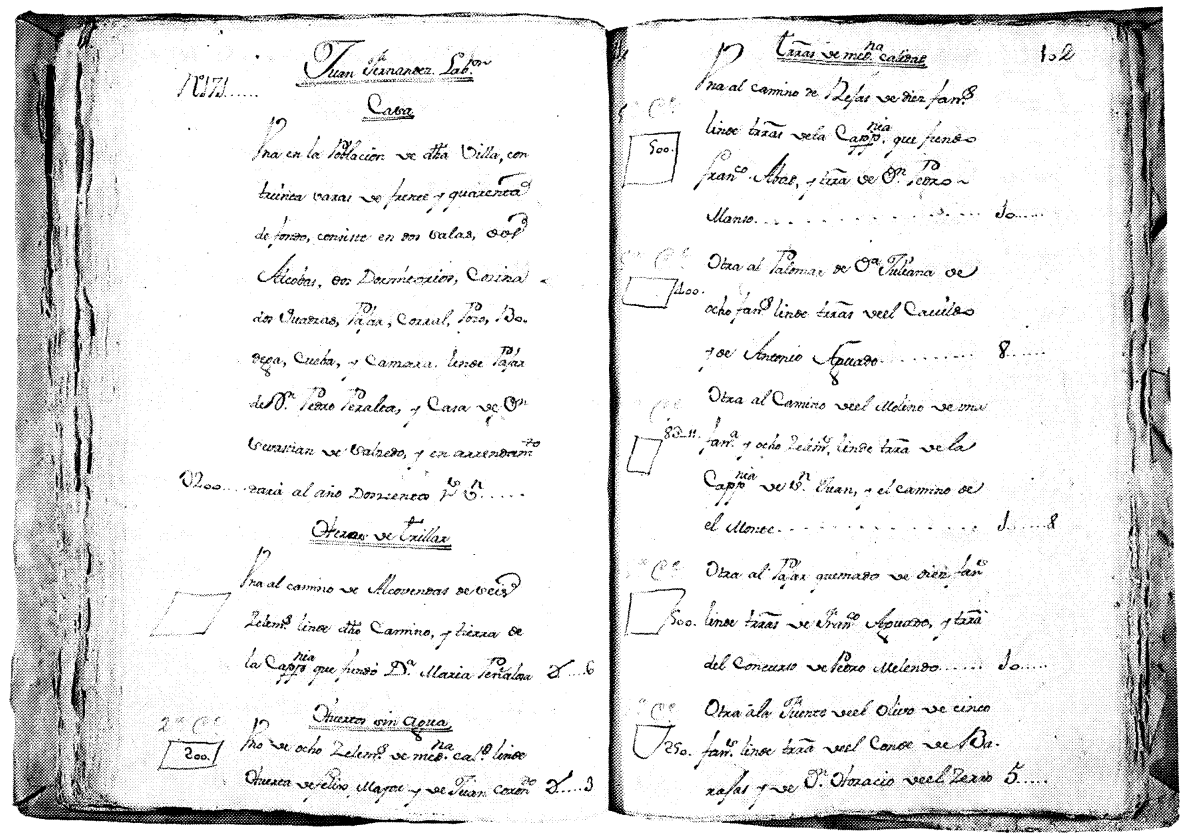

Copia del Libro de lo real de legos de la Villa de Barajas (Madrid), enviado al ayuntamiento en 1759 (Archivo de Villa, Madrid).

lo real que se enviaron a todos los pueblos en 1759. Nos consta que en el proceso reciente de catalogación de fondos municipales que se está llevando a cabo de forma bastante generalizada se están encontrando muchos de esos documentos, como ha ocurrido, por ejemplo, en Tordesillas, Sigüenza, Gumiel de Hizán, San Sebastián de los Reyes, Quintanar de la Sierra, Sanlúcar de Barrameda, Carmona, etcétera.

Dicho esto me referiré a un aspecto nuevo: constatar cómo en algunos lugares se produjo una superposición de actividades cartográficas, relacionando en el tiempo y en el espacio la confección del Atlas de España con el catastro. Basten dos ejemplos.

En 1750 se da la orden de cartografiar técnicamente la provincia de Murcia, que dependía entonces de la Intendencia de ejército con capital en Valencia. Dicha orden fue cursada por la Junta al intendente valenciano, el marqués de Malespina, dándole cuenta de «haber resuelto S.M. que V.S. pase luego al Reyno de Murcia, y ejecute en él lo que com- 
prehende la Instrucción de Única Contribución», a la vez que se le avisa de que «se destinarán uno o dos Ingenieros para que levanten los Planos del citado Reyno, vajo las órdenes de V.S., con toda la debida individualidad y puntualidad».

El segundo caso se da a lo largo de toda la frontera con Portugal, limitándonos aquí a uno de los términos allí existentes, el de Bouza. Dicha villa se hallaba «en la raya y confín que divide el Reyno de España del de Portugal por la parte de Ciudad Rodrigo", estando los mojones establecidos a lo largo del arroyo Turones. Ofrecía la particularidad de que, siendo territorio castellano, «su jurisdicción, diezmos y otros derechos señoriales» pertenecían al abad y al convento portugués de Ntra. Sra. de Aguilar, o Aguiar, de la Orden de San Bernardo, «por donación pura e irrevocable que le hizo el Rey de León Dn. Alonzo, a los 20 de Agosto de el año de 1249», estando ahora el monasterio ubicado dos leguas adentro en territorio portugués. Ello hace que los del pueblo, todos ellos jornaleros, se nieguen a confirmar lo ordenado para el catastro, hasta que averiguó el subdelegado que todo el término se hallaba comprendido dentro de los dominios de España, como evidenciaba «el Plan que levantó Dn. Antonio Gaver, Ingeniero en Gefe de los Ejércitos de S.M.», mapa que, paradójicamente, había sido conformado por el alcalde y regidores de Bouza. Tal circunstancia lleva a que entre la documentación catastral se encuentre la elaborada por Antonio de Gaver en julio de 1751.

El levantamiento cartográfico, ordenado por Ensenada, que comprendió «las cuatro provincias que hazen frente y dividen el reyno de Portugal hasta este lugar de Bouza», ofrece el interés añadido de que Gaver no se contentó con cartografiar los términos de frontera, sino que fue recabando, tal como ordenaba la Instrucción de ingenieros, de los pueblos y mediante observaciones propias, centenares de datos que constituyen una documentación paralela, y a veces complementaria, a la Respuestas generales de los términos cartografiados. Gaver llegó a Bouza el 23 de julio de 1751, acompañándole Francisco Hurrutia, capitán de infantería e ingeniero ordinario, dos soldados de caballería «y otros algunos Inválidos que tienen destino en el Real Fuerte de la Conzepción», así como un escribano. El alcalde, Manuel Gómez, no opuso entonces dificultad alguna, designando tres peritos locales, «ancianos y fidedignos», para señalar a Gaver los límites exactos del término. Gaver lo recorrió, «asentó la plancheta en distintos altos y parajes», averiguó sus dimensiones y representó «según preceptos de el Arte» sus lomas y cerros, 
su amplio rebollar, sus muchos pedruscos y las tierras labrantías, entre ellas, «una viña zercada de pared de pizarra, que se cultiva a azada y que quenta con casa y lagar de viga y pesa de piedra». Posteriormente, el ingeniero obtuvo información del alcalde y ancianos: que las tierras se cultivaban a tres hojas (Valdenegros, La Granja y Turones), que todas ellas eran débiles y trabajosas «al rozarlas y cultivarlas», por lo que se destinaban a centeno, obteniendo una cosecha media anual de 1.200 fanegas; que aun siendo colonos pagaban diezmos de granos y ganados; que la viña rendía al monasterio doscientos cántaros de vino; que cada colono pagaba anualmente una gallina «por feudo o basallaje»; que la hoja que cada año quedaba en rastrojo se destinaba a los bueyes de labor, mientras que la de erial y barbecho era aprovechada por el ganado lanar, cabrío y de cerda; que la única iglesia del pueblo era una ermita, donde estaba la patrona, la Virgen de la Oliva; que las casas eran todas «tejivanas, de ynútil fábrica y cubiertas las más de escoba y paja», siendo obligado la obtención de permiso del monasterio para levantarlas o ampliarlas, etc. En definitiva, multitud de datos complementarios de los estrictamente cartográficos. Gaver se ajusta en su trabajo en Bouza a lo establecido en la real Ordenanza e Instrucción de Ingenieros, tal como apenas diez años antes hiciera A. Riviere en Canarias.

Resumiendo lo expuesto hasta aquí cabe afirmar que el catastro, de forma general, da lugar a dos tipos de informaciones de interés cartográfico: las representaciones de los términos y las figuras de las piezas de tierra existentes en todos ellos. Genera también diversas descripciones (términos confinantes, ríos, puentes, caminos) que enriquecen sobremanera aquéllas. A todo ello se añade lo que podría calificarse de «cartografía excepcional», de la que son ejemplos los casos analizados de Murcia y Bouza. Pertenecerían asimismo a tal tipología los mapas que se levantaron para decidir con mejor fundamento en los casos, frecuentísimos, de conflictos entre términos o entre villas y aldeas o arrabales por razones de límites o por cuestiones de jurisdicción, ya que se había ordenado que se operaran como pueblos separados todas aquellas entidades que tuviesen término y jurisdicción propios, bastando a veces para actuar en ese sentido el que constituyesen alcabalatorios o dezmerías independientes; por ello no accedió la Junta a la pretensión del cabildo de Córdoba de operar conjuntamente una serie de términos en los que tenía bienes y derechos; su solicitud llegó acompañada de un mapa del término de Córdoba con las 17 «jurisdiziones o villas despo- 
bladas ${ }^{6}$. Fue también fuente de cartografía excepcional la denuncia de casos de rompimientos u ocupaciones de baldíos sin título para ello. Dos situaciones más dan lugar a algunos levantamientos cartográficos: la condición de Sitio Real y la pretensión de hacer méritos, de lo que dio magníficos ejemplos el subdelegado Pedro Padilla, que de esa forma pensaba granjearse una especial estima por parte de Ensenada, lo que es muy elocuente de la imagen que tenían de él algunos funcionarios ${ }^{7}$.

En cuanto a los conflictos entre pueblos confinantes como fuente de cartografía hay que señalar que las operaciones catastrales fueron una excepcional ocasión para aclarar y fijar sus demarcaciones, intentando el acuerdo entre todos los interesados. Un buen ejemplo al respecto es el proceder de la villa conquense de Roda, que manifiesta en el Interrogatorio que no podía dar el dato de las medidas de tierra de su término sin proceder a su apeo, para lo que propone al subdelegado, Manuel Thomás de Neri, y a las villas confinantes el hacerlo con toda formalidad. Dice que actuando así se daría cumplimiento «a las Reales Leyes y autos acordados del Supremo Consejo» para que anualmente, o al menos cada tres años, se procediera a renovar los deslindes y amojonamientos. Hechas las oportunas requisitorias, y fijados el día y hora en la que deberían concurrir a los linderos los comisarios designados, no se presentaron los de Fuensanta ni los del Cerro, de la que era señor Rafael Valdés, vecino de Villanueva de los Ynfantes, villa ésta también confinante y antigua «hijuela segregada de ella». Ante tales incomparecencias, Roda remite un mapa propio a Ensenada, a la vez que le instaba a ordenar que acudiesen a los fines señalados. La Junta se limitó en este caso a ordenar al intendente que tomase las providencias pertinentes, «solo para el intento de este establecimiento, sin exceder ni hazer perjuicio al derecho de los derechos confinantes».

\footnotetext{
${ }^{6}$ Puede verse dicho mapa en LóPEz OnTiveros, A. (1990): Córdoba en 1752 según las Respuestas Generales del Catastro de Ensenada. Madrid, Centro de Gestión Catastral y Cooperación Tributaria y Tabapress, Colección «Alcabala del Viento», n. ${ }^{\circ} 3$, pág. 15. En dicha colección se han publicado las Respuestas Generales de más de 75 lugares, reproduciéndose sus respectivos mapas cuando éstos se han conservado. Son interesantes, por ejemplo, los incluidos en los libros dedicados a Valdepeñas, Oviedo, Fuentevaqueros, Quintanar de la Sierra, Porcuna, Montefrío, etc. Asimismo, se han incluido algunos mapas de pueblos de León-Asturias y Jaén en CAMARERo, C. y CAMPOS, J. (1991): Vecindario de Ensenada, 1759. Madrid, Centro de Gestión Catastral y Cooperación Tributaria y Tabapress, Colección «Alcabala del Viento», serie alfabética, libro B, vol. IV.

7 Dos de los mapas enviados por Padilla, el de Jódar y el de Cabra de Santo Cristo, pueden verse en CAMARERO, C. (1989): Op. cit., pág. 193.
} 
Ejemplos de mapas levantados por la comprobación de rompimientos ilegítimos de tierras fueron los levantados de Utrera y otros pueblos de la campiña sevillana, de los que decía el intendente que, aunque «no trascienden a la propiedad», suponen culpa porque se aprovechan indebidamente «de lo realengo». Dice después haber ordenado al alguacil mayor de la villa que proceda a la medición de todos los baldíos apropiados o disfrutados para tomar después las providencias que se consideren oportunas. A propósito de esto, y como inciso, conviene saber que en Sevilla las mediciones de tierras se realizaron ordinariamente con tazmiadores no avecindados en los términos que medían, pues el intendente pensó que, existiendo fincas de tan gran extensión y crecido producto, el fraude sería muy importante a poco que se rebajaran una u otro, y que, perteneciendo las mismas a «grandes, a sus administradores, a comunidades y personas distinguidas», aun cuando los pueblos saliesen perjudicados por deber contribuir más los vecinos, «sus patricios no se atreverían a deponer contra aquéllos por necesitarles para su subsistencia». Por cierto, el intendente hablaba con sumo elogio de Francisco Román, tazmiador vecino de Utrera, que midió las tierras de Molares, Coronil, Puebla, Morón, Marchena y otros, siendo tal su pericia que en un pueblo «dio puntual razón en sólo dos dias de cien mil aranzadas de tierra».

En cuanto a los Sitios Reales, la Instrucción no exceptuaba de las averiguaciones persona alguna ni más bienes raíces que los lugares sagrados. No obstante, por la formal confusión existente según la cual no existía clara distinción entre bienes públicos y bienes del rey, pareció a muchos que los Reales Sitios no debían ser objeto del catastro, pues no tenía lógica que el monarca contribuyera para sí mismo. De ahí que asistamos a las dos actitudes, la de quienes pensaban que si nada quedaba exento tampoco esos sitios, y la de quienes entendían que los mismos gozaban de exención intrínseca. Serán los primeros quienes formularán consultas sobre si se debía o no intentar averiguar determinado sitio real. El intendente de Granada, el marqués de Campoverde, preguntaba, por ejemplo, si debían o no describirse determinados bienes realengos, como el Real Sitio de El Soto de Roma. A Ensenada le llegaron también las consultas y pareceres de los propios gobernadores de los Reales Sitios; así, el del Soto de Roma, Manuel Arista y Morón, le manifestaba que la averiguación debería «ejecutarse en quanto a las posesiones de particulares que están intrusas en dicha jurisdicción, pero no en quanto a 
las que corresponden al Patrimonio Real, tanto por no tener orden para dar las relaciones juradas, como porque, sin dispendio alguno a la Real Hacienda, puedo hazerlas yo, y darlas, o al Yntendente de esta Provincia, o pasarlas en derechura a manos de V.E.», en prueba de lo cual remitió un precioso mapa, en el que se advertía haber representado el nuevo cultivo de maíz y la plantación de más de 50.000 moredas para mejorar su rentabilidad, pues Ensenada forma un plan riguroso para que todos los Sitios Reales o ganen dinero o al menos se autofinancien ${ }^{8}$.

Finalmente, es reseñable cómo, tras el catastro, la propia Administración empieza a hacer uso de mapas y datos para fines de mejor gobierno. En marzo de 1757, Miguel Ric, Ministro del Real y Supremo Consejo de Castilla, juez de la Comisión para la Conservación y Aumento de Montes y Plantíos en un círculo de 25 leguas alrededor de la Corte, solicita certificados referidos a todos los pueblos y lugares del partido de Cuenca en los que debía constar todo lo referente a la medida del término, número de tierras de labor, así como de montes y plantíos, señalando en su escrito expresamente que los datos que se le diesen fuesen «todos ellos con arreglo a la demarcazión judicial que se ejecutó con motivo de las diligencias de Única Contribuzión». Se le responde diciendo que está prohibido por la Junta dar tales datos, optando Ric por ordenar a cada uno de los pueblos que las justicias le entregasen los correspondientes certificados, dirigiéndose entonces ellos a la Junta exponiendo «el perjuicio, dilazión y gastos que se les causa en el hecho de precisarles a un nuevo apeo y deslinde de sus términos». $\mathrm{Al}$ mismo tiempo, Ric se dirigió también a la Junta, dándole cuenta de estar comisionado por el monarca para «justificar las fanegas u obradas de tierra que ocupan los montes viejos de enzina, roble, y pino, los tallares de corta, y los de siembra nuevamente establecidos, existentes en la jurisdicción de mi encargo».

Otros puntos que no cabe desarrollar por razones de espacio, pero que sí es interesante dejar apuntados, son los siguientes:

1. La validez del catastro para confeccionar el nomenclátor de las Castillas, tanto de términos jurisdiccionales como de pagos o sitios de

8 Véase Camarero, C. y Campos, J. (1991): «Notas en torno al Real Sitio del Soto de Roma y su catastro», en FERnández MonTEsinos, M.: Soto de Roma en 1753 según las Respuestas Generales del Catastro de Ensenada. Madrid, Centro de Gestión Catastral y Cooperación Tributaria y Tabapress, Colección «Alcabala del Viento», n. ${ }^{\circ} 7$ págs. 21 a 55. 
todos esos términos. Baste decir como ejemplo que antes de realizar el catastro en la Contaduría de Burgos constaban sólo 883 pueblos, resultando haber 1.849 con jurisdicción propia.

2. La validez también para la recomposición de la red caminera, incluidos caminos reales, carreteros, de herradura y simples veredas, descritos todos ellos en los asientos de las tierras, en los Libros de lo real.

3. La validez asimismo para el dimensionamiento de todos los cascos habitados, pues constan las casas y edificios varios con sus dimensiones y confrontaciones.

4. El interés también para la reconstrucción de los espacios de montes, bosques, dehesas, prados, tierras comunales y de propios, comunes y ledenías.

5. Su utilidad también para la recomposición de las provincias de entonces, con sus múltiples enclaves extraterritoriales, y con toda la complejidad jurisdiccional de la época. Asimismo, para el conocimiento exhaustivo de los despoblados y cotos redondos.

6. Cabe también señalar el gran interés que ofrece la cartografía catastral, precisamente por su rudeza y simplicidad, para realizar un completo estudio de cómo se percibía el espacio y cómo se reflejaba en sus representaciones: la desmesura en el ancho de los cursos de agua, la desproporción con que se señalan los molinos, batanes, iglesias, castillos, la simbología utilizada para representar otros accidentes, las denominaciones utilizadas para los puntos cardinales, la orientación que se da a las representaciones, etcétera.

Tras lo aquí recogido, sería de desear que la sencilla cartografía del catastro merezca una mayor atención por parte de cartógrafos, geógrafos, historiadores y estudiosos en general.

RESUMEN: La Cartografía en el Catastro de Ensenada, 1750-1756. En este trabajo se estudian cuáles fueron los propósitos y resultados cartográficos que respectivamente abrigaron y obtuvieron los diseñadores y realizadores de la averiguación catastral llevada a cabo en la Corona de Castilla entre 1750 y 1756, conocida como Catastro de Ensenada. Recoge: 1) las principales características del catastro en cuanto marco general en el que se genera un importante conjunto de representaciones de carácter cartográfico no técnico, 2) la normativa que se dicta para la obtención de dichas informaciones, así como la marcha atrás que se produce cuando se constata la escasez de geómetras y se valora debidamente el tiempo que se precisaría para medir y representar con exactitud los miles de términos que había que catastrar, 3) los resultados cartográficos obtenidos y 4) los do- 
cumentos en los que quedaron plasmados y el uso de los mismos que puede hacerse. Finalmente, se resalta la contemporaneidad entre el primer intento institucional para elaborar el Atlas de España y la cartografía catastral, que se puede calificarse de «popular» por haber sido elaborada, salvo contadísimas ocasiones, desde el desconocimiento de los principios del Arte correspondiente.

PAlabras Clave: Corona de Castilla. Catastro de Ensenada. Cartografía. Siglo XvIII. Geografía histórica. Fuentes geohistóricas.

RÉSUMÉ: La Cartographie du Cadastre de Ensenada, 1750-1756. Dans ce travail nous étudions quelles étaient les propos et les résultats cartagraphiques qui orientèrent et que les dessinateurs-cartographe et realisateurs obtinrent de la recherche cadastrale menée à bout sous la couronne de Castille entre 1750 et 1756, connue comme Cadastre de Ensenada.

Il recueille: 1) les principales caractéristiques du cadastre considéré comme le cadre général où va se créer un groupe important de représentation de caracter cartographique non technique, 2) la nome qui se dicta pour l'obtention de ces informations ainsi comme le revirement qui se produisit lorsque l'on constata le manque de géomètres et que l'on calcula dûment le temps qu'on allait mettre pour mesurer et représenter avec exactitude les milles parcelles foncièrs qu'il fallait cadastrer, 3) les résultats cartographiques obtenus et 4) les documents oú ils furent reflétés et l'usage que l'on peut faire des mêmes.

Finalement, on célèbre la contemporanéité entre le premier essai institutionnel pour élaborer l'Atlas d'Espagne et la cartographie cadastrale, qui peut se qualifier comme «populaire» puisqu'il fut conçu, sauf quelques exeptions, à partir des défauts de connaissances des principes de l'art correspondant.

Mots CLÉ: Couronne de Castilla. Cadastre de Ensenada. Cartographie. XVIII ème siècle. Géographie historique. Sources geohistoriques.

ABSTRACT: The Cartography in the Ensenada Cadastre. 1750-1756. In this work the author reflects on the cartographical aims and results that were designed and obtained through surveys in the Crown of Castille between 1750 and 1756, known as the Ensenada cadastre. This article covers the main characteristics of the cadastre as general background where an important set of representations are produced. These representations are of a non-technical cartographical character. Along with this, the author lists the rules required in order to obtain significant information and the «reversing» of the process once realised the lack of specialists in geometry. As a result of this, they became aware of the amount of time that would be needed in order to measure and represent accurately the thousands of terms that had to be surveyed. But this was not the only drawback as appropriate documents had to be written with the results of the census. The surveyors also had to decide on the use to be given to these documents.

Finally this article states that the first institutional attempts to elaborate the Atlas of Spain and the unofficial cartographical cadastre took place at the same time. This «unofficial» cartography can be called so, because mostly it was carried out not knowing the principles of cartography.

KEY wORDS: Crown of Castille. The Ensenada cadastre. Cartography. The 18th century. Historical Geography. Geohistorical sources. 